\title{
DESIGN OF LaPO ${ }_{4}: \mathrm{Nd}^{3+}$ MATERIALS BY USING IONIC LIQUIDS
}

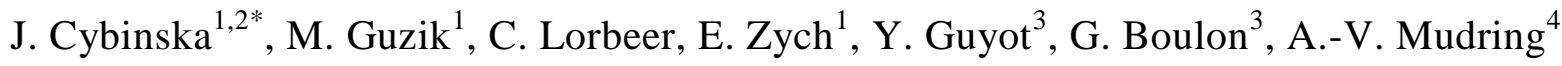 \\ ${ }^{1}$ Faculty of Chemistry, University of Wroctaw, 14 F. Joliot-Curie, 50-383 Wrocław, Poland \\ ${ }^{2}$ Wroclaw Research Centre EIT+, Stablowicka 147, 54-066 Wroclaw, Poland \\ ${ }^{3} 3$ Univ Lyon, Université Claude Bernard Lyon1, CNRS, Institut Lumière Matière, F-69622, \\ Lyon, France \\ ${ }^{4}$ Department of Materials Science and Engineering, Iowa State University and Critical \\ Materials Institute Ames Laboratory, IA 50011, USA
}

*corresponding author: joanna.cybinska@chem.uni.wroc.pl

\begin{abstract}
Monoclinic monazite-type $\mathrm{Nd}^{3+}$-doped lanthanum orthophosphate $\left(\mathrm{LaPO}_{4}: \mathrm{Nd}^{3+}\right)$ nanoparticles were prepared by microwave treatement of simple lanthanide precursors such as $\mathrm{Nd}(\mathrm{OAc})_{3} \bullet \times \mathrm{H} 2 \mathrm{O}, \mathrm{OAc}=$ acetate $)$ with task-specific dihydrogen phosphate ionic liquids (ILs) 1-butyl-1-methylpyrrolidinium dihydrogenphosphate- $\mathrm{BmPyrH}_{2} \mathrm{PO}_{4}$ (IL 1) and 2hydroxyethyl-N,N,N-trimethylammonium, [choline] $\left[\mathrm{H}_{2} \mathrm{PO}_{4}\right]$ (IL2) as the reaction medium, reactant and in-situ nanoparticle stabilizer and templates at $140^{\circ} \mathrm{C}$ within 10 minutes. This synthesis route possesses many advantages as it is a fast and facile preparation method for the desired phosphate nanomaterials without the necessity for post-reaction heat treatment to obtain the anhydrous high temperature monazite phosphate phase.
\end{abstract}

The nano-sized phosphors $\mathrm{Nd}^{3+}: \mathrm{LaPO}_{4}$ were carefully analyzed by the powder $\mathrm{X}$-ray diffraction, electron microscopy and spectroscopic techniques taking advantage of the $\mathrm{Nd}^{3+}$ spectroscopic probe to analyze in detail the structural properties. Applied high resolution low temperature absorption and emission techniques allowed to complete the structural information unavailable from the XRD powder patterns.

A clear influence of the used task-specific dihydrogen phosphate ILs on the structure, morphology, luminescence intensity and lifetimes of the obtained $\mathrm{Nd}^{3+}: \mathrm{LaPO}_{4}$ was found. It is worth noting that the $\mathrm{Nd}^{3+}$ luminescence in $\mathrm{LaPO}_{4}$ has never been reported up to now.

Keywords: orthophosphates, ionic liquids assisted synthesis, neodymium doping, NIR emitting phosphors 


\section{Introduction}

In the modern technology functional nanomaterials plays very important role, thus as the morphology - size and particles shape influence the physico-chemical properties of these materials, it is crucial to develop synthesis protocol which allows to obtain well reproducible particles. In materials with good optical properties, for transformation from bulk or crystals to the nanometric scale phosphors it is necessary to consider all the advances like for example reduced light scattering and avoiding unwanted drawbacks, such as a high surface defect concentration, which is likely to result in luminescence quenching. From a spectroscopic point of view the large surface of nanoparticles (NPs) is without a doubt critical, and fundamental luminescence properties such as decay times and non-radiative as well as radiative relaxation paths are strongly affected. For these reasons, extreme care must be taken in order to find ways to fabricate nanometer-scale phosphor materials with good optical properties. Among the techniques for phosphor materials, which was applied lately in different nanomaterials preparation, such us, fluorides, oxides, or phosphates, nanomaterials the synthesis with using Ionic Liquids (ILs) seems to be very promising one [1-5]. The advantages of ILs in nanoparticle synthesis in comparison with other methods of preparation of nanomaterials were presented in the detailed description in [6].

In this method ionic liquids can be not only reaction medium but also reactant [6-10]. From chemical point of view ILs are considered to be generally ionic organic compounds, with melting point below $100^{\circ} \mathrm{C}$, many of them are even already liquid at room temperature (RTILs). The physicochemical properties of ILs as thermal stability, viscosity, density, melting temperature can be modify by selecting appropriate cations and anions. The extremely low vapor pressure and non-flammability of most ionic liquids makes them good candidates to replace some organic solvents. The number of potential cation/anion modification seems to be unlimited. This offers the possibility to design an IL with properties for a specific application (task-specific ionic liquids, TSILs). It is also possible to use these salts as a template for nano-particles synthesis, and by changing the cation or anionic part in ILs one can change size and shape of the synthetized nanomaterials. A strong influence on the size and morphology of the obtained particles can be expected, as ionic liquids can work as a template and in-situ stabilizing preventing the particles grow and agglomeration [6-8, 10,11]. Up to the date detailed studies of influence ILs composition on the optical properties of lanthanide doped fluorides and phosphates were reported [6-8, 10,11].

The orthophosphates doped with optically active lanthanides ions were studied over many years as these crystal lattices are matrices with high mechanical and chemical performances. 
For the doping of trivalent rare earth ions no charge compensation is required. With relatively large band gap they open possibility to observe an efficient emission of optically centers in Vis and/or IR spectral ranges [12-15]. They are extensively studied as phosphors, scintillators and laser materials. The $\mathrm{Nd}^{3+}$ activated phosphates are very popular among researchers. As example we can mention the $\mathrm{LuPO}_{4}: \mathrm{Nd}$ and $\mathrm{YPO}_{4}: \mathrm{Nd}$ as new promising VUV scintillation materials [16] or neodymium ultra-phosphate (penta-and tetra phosphates) crystals, which belong to the group of high concentration neodymium stoichiometric laser materials, where weak concentration dependence of $\mathrm{Nd}^{3+}$ fluorescence is predominantly associated with a large distance $\left(6.6 \AA\right.$ ) between neighboring $\mathrm{Nd}^{3+}$ ions resulting in reduced concentration quenching [17-21].

Lately many studied were devoted to the orthophosphate materials in nanoscale as they can find many applications, also in bio imaging [22]. These materials doped with optically active lanthanide ions have properties as narrow emission bands, with submilliseconds lifetimes of the emitting metastable levels which make them good candidate for fluorescent agents. Very important requirement for this purpose is the location of excitation and emission bands, which should be in the spectral range $800-1300 \mathrm{~nm}$, thus in the transparency window of biological tissues. It also prevents high autofluorescence of tissues. One of lanthanides ions, which fulfil this demand is $\mathrm{Nd}^{3+}$ ion, showing relatively efficient NIR luminescence. It is well known, because of nanoparticles big surface to volume ration these materials show less intensive emission than the crystals, or bulk as the nonradiative processes of the deexcitation can be promoted by the water and other impurities bounds on the surface. In the case of the fluorescence in the UV region the contribution of the quenching caused by $-\mathrm{OH}$ groups to the overall relaxation rate is not so significant due to very high energy of optical transitions. However, this effect can plays significant role especially in quenching emission in infrared range. This obstacle is a fundamental one, as most of the methods of synthesis of water dispersible nanoparticles are carried out either in water or in other $-\mathrm{OH}$ containing media. Later the molecules of water can be removed only by high temperature treatment accompanied by agglomeration of the NPs with an expected loss of dispersibility.

This is why we would like to perform the studies of $\mathrm{Nd}^{3+}$ activated $\mathrm{LaPO}_{4}$ prepared by using earlier reported method of synthesis of nanoscale orthophosphate with ILs, which allow to synthetized anhydrous materials at relatively low temperature. The $\mathrm{Eu}^{3+}$ ions doped materials showed relatively high luminescence, and the impurity traces did not efficient quench luminescence [6,11]. We applied above preparation protocol to synthetize $\mathrm{LaPO}_{4}: \mathrm{Nd}^{3+}$ materials, in aim to study the influence of ILs on the morphology of obtained 
particles on their NIR emission performance. The $\mathrm{Nd}^{3+}$ luminescence in $\mathrm{LaPO}_{4}$ has never been reported up to now.

\section{Materials and characterizations}

\subsection{Synthesis of $\mathrm{Nd}^{3+}$-doped orthophosphates using ILs as reaction media}

The studied nano-powdered samples were synthesized according the procedure described earlier in $[6,11]$. In this synthesis protocole lanthanides precursors, which are the simple lanthanide salts like nitrate or acetate hydrates are converted at relatively low temperature $\left(\sim 140^{\circ} \mathrm{C}\right)$ to anhydrous lanthanide phosphate. A phosphate ionic liquid is used as the reactant and phosphate group donor. By applying such a synthesis protocol it is possible to obtained relatively phosphate particles small (even below $10 \mathrm{~nm}$ ) as ionic liquid (IL) also prevent the formed nanoparticles from agglomeration and coalescence to the bulk.

In order to obtain $\mathrm{LaPO}_{4}: \mathrm{Nd}^{3+}$ nanomaterials the proper mixture of $\mathrm{Ln}$ (III) acetate hydrate and $\mathrm{Nd}(\mathrm{III})$ acetate hydrate was dissolved in small amount of ethylene glycol and then excess amount of ILs (1-butyl-1-methylpyrrolidinium dihydrogenphosphate, $\mathrm{BmPyrH}_{2} \mathrm{PO}_{4}$ (IL 1) and 2-hydroxyethyl-N,N,N-trimethylammonium dihydrogenphosphate, [choline] $\left[\mathrm{H}_{2} \mathrm{PO}_{4}\right]$ (IL2), see Fig. 1). Usually the reactant ratio was of $150 \mathrm{mg}$ of lanthanide(III) acetate and $0.3 \mathrm{~g}$ of ILs. The reaction solution was stirred until homogeneity is reached and then placed in a 10 $\mathrm{ml}$ microwave reaction vessel. The reaction was carried out in two steps - first heating to $60^{\circ} \mathrm{C}$ for 10 minutes and then increasing the temperature to $140^{\circ} \mathrm{C}$ for another 10 minutes using a single mode microwave (CEM Discover, Kamp-Lintfurt, Germany) operating at $2455 \mathrm{MHz}$. The post reaction colloidal solution was centrifuged and the powdered material was washed with ethanol and dichloromethane. The obtained powder was dried at $100^{\circ} \mathrm{C}$ for $12 \mathrm{hrs}$.

The preparation of samples under investigations can be described by the following equation:

$$
\mathrm{Ln}(\mathrm{OAc})_{3}+[\mathrm{cat}]\left[\mathrm{H}_{2} \mathrm{PO}_{4}\right] \rightarrow \mathrm{LnPO}_{4} \downarrow+2 \mathrm{HOAc} \uparrow+[\mathrm{cat}][\mathrm{OAc}] \text { (1) [11] }
$$

$\mathrm{Ln}=$ lanthanide; OAc = acetate, $[\mathrm{cat}]-1$-butyl-1-methylpyrrolidinium dihydrogenphosphate$\mathrm{BmPyrH}_{2} \mathrm{PO}_{4}$ (IL 1) and 2-hydroxyethyl-N,N,N-trimethylammonium, [choline] $\left[\mathrm{H}_{2} \mathrm{PO}_{4}\right.$ ] (IL2).

With these two ionic liquids anhydrous lanthanide phosphates $\mathrm{LnPO}_{4}$ were obtained directly from the process even at low temperatures $\left(\mathrm{T}=140^{\circ} \mathrm{C} / 10 \mathrm{~min}\right)$ without the need for a post reaction heat treatment. 
For $\mathrm{LaPO}_{4}$, two modifications are known in the bulk materials and crystals: the low temperature monoclinic phase of $\mathrm{LaPO}_{4}$ (tysonite type of structure) with rreversibly undergoes a phase transformation to the monazite structure above $600^{\circ} \mathrm{C}$. Using IL as reaction medium, in situ stabilizer and donor of phosphate group lead to high temperature phase already at $140^{\circ} \mathrm{C}$.

\subsection{Sample characterization}

\section{XRD phase analysis}

The powder X-ray diffraction patterns were collected at room temperature by using a D8 Advance X-ray diffractometer (Bruker). The measurements were performed within the range $10-60^{\circ} 2 \theta$ with a scan rate of $0.008^{\circ}$ per step and a counting time of $5 \mathrm{~s}$ per step. For the experiments nickel-filtered $\mathrm{CuK}_{\alpha}$ radiation $\left(\mathrm{K}_{\alpha 1+2}, \lambda=0.15418 \mathrm{~nm}\right)$ was used.

\section{FT-IR measurements}

FT-IR spectra of powdered samples in the $3800-300 \mathrm{~cm}^{-1}$ spectral range were measured using at Specord-M-80 spectrometer (Carl Zeiss Jena). The powdered samples were mixed with Nujol oil (a mixture of liquid hydrocarbons). The spectral resolution of FT-IR measurement was $2 \mathrm{~cm}^{-1}$.

\section{Scanning electron microscopy (SEM) and Transmission electron microscopy (TEM).}

Scanning electron microscopy (SEM) studies were carried out on a Hitachi S-3400N equipped with an energy dispersive X-ray spectroscopy (EDX) EDAX analyser. The powders were coated with a thin gold alloy layer to facilitate conductivity.

Transmission electron microscopy (TEM) measurements were carried out on a Tecnai G2 20 X-Twin TEM (Fei, Hillsboro, USA) or a H-8100 TEM of the Hitachi company (Tokyo, Japan) equipped with a Penta FET EDX detector (Oxford Instruments, UK). An acceleration voltage of $200 \mathrm{kV}$ was applied. To prepare the samples, a suspension of the sample in ethanol was dropped on a copper or gold grid coated with carbon and then dried in air.

\section{Absorption measurements}

Absorption spectra in the 200 - $2500 \mathrm{~nm}$ spectral range were recorded at 4 and $293 \mathrm{~K}$ with a Cary-Varian 5000 Scan spectrometer equipped with an Oxford CF 1204 helium flow cryostat. The pellets used for the absorption measurements were prepared under $20 \mathrm{MPa}$ pressure during 5 minutes.

\section{Luminescence decay measurements}

The luminescence decay curves were recorded under pulsed laser excitation (OPO laser, EKSPLA NT342, 10Hz, $7 \mathrm{~ns}$ ), the fluorescence intensity around $1 \mu \mathrm{m}$ being detected with a 
R1767 Hamamatsu photomultiplier through a HRS1 Jobin-Yvon monochromator equipped with a $1 \mu \mathrm{m}$ blazed grating and coupled to a LECROY LT 342 digital oscilloscope. Both the luminescence emission spectra detected with the help of an IR Hamamatsu CCD camera and decay curves were recorded at room and liquid nitrogen temperature. As an excitation source also LED $\left(\lambda_{\mathrm{ex}}-590 \mathrm{~nm}\right)$ and $\mathrm{Ar}^{+}$laser have also been used.

\section{Results and discussion}

\subsection{XRD analysis of phosphates nano-powders}

Lanthanide (RE) orthophosphates are very well known, being stable materials. They can be found in nature as minerals existing in two common phases - monazite and xenotime. Depending on the ionic radius of the rare earth ion either the monazite or xenotime structure is the thermodynamically stable phase. In both types of structure the atomic arrangements is characterized by chains of interconnected phosphate tetrahedra and RE polyhedral. These are in case of the xenotime structure with is preferentially adopted by the smaller RE (Y, Tb-Lu) a $\mathrm{REO}_{8}$ polyhedron (distorted square anti-prism) and $\mathrm{REO}_{9}$ polyhedron (fairly distorted tricapped trigonal prism. In both structures the $\mathrm{PO}_{4}$ are isolated, separated by $\mathrm{LnO}_{\mathrm{x}}$ polyhedra [23-26]. Low temperature hydrated rhabdophane with a general formula $\mathrm{REPO}_{4} \cdot \mathrm{nH}_{2} \mathrm{O}(\mathrm{RE}$ : $\mathrm{La} \rightarrow$ Dy) has been considered to crystallize in the hexagonal [26] system. However, recent investigations show that the structure of this compounds is rather monoclinic than hexagonal and that it can be found for Ln = La-Dy [26]. It was found that this phase irreversibly transforms to monazite after heating to $600^{\circ} \mathrm{C}$.

Fig. 2 presents the visualization of the polyhedral view of $\mathrm{PO}_{4}$ tetrahedra and $\mathrm{REO}_{9}$ polyhedra in the structures of monazite type $\mathrm{LaPO}_{4}$ (Fig.2a) and $\mathrm{PO}_{4}$ tetrahedra and $\mathrm{REO}_{8}$ polyhedra (Fig.2b) in hexagonal rhabdophane type orthophosphates. This hexagonal structure is made of $\mathrm{PO}_{4}$ tetrahedron and $\mathrm{LaO}_{8}$ polyhedra linked together to form chains alternating $\mathrm{PO}_{4}$ and $\mathrm{LaO}_{8}$ polyhedron. The chains are linked together by $\mathrm{P}-\mathrm{O}-\mathrm{La}$ bonds leaving an open channel along the hexagonal axis. The open channel has a minimum diameter of $3.4 \AA$ and can contain $0-1$ mol of water molecules [27] The zeolitic water in the hexagonal rhabdophane type (for hydrated) evaporates between $180^{\circ} \mathrm{C}$ and $280^{\circ} \mathrm{C}$. [24]

In Fig. 3 we present the X-ray powder diffraction pattern of $\mathrm{Nd}^{3+}$-doped $\mathrm{LaPO}_{4}$ obtained from (IL2) together with the simulated XRD patterns of monazite type $\mathrm{LaPO}_{4}$ (ICSD\#01-0716745). The insert contains the simulated patterns (taken from the Database of Inorganic Crystal Structure XRD) of monazite and rhabdphane phases. It is presented to clearly point out on the difference in the localisation of the reflections of both phases. Thus for $\mathrm{Nd}^{3+}$-doped $\mathrm{LaPO}_{4}$ (IL2) sample the XRD patterns in the $2 \theta$ range of $15-60$ corresponds very well to 
monoclinic phase. Despite the large width of registered peaks all reflections fit perfectly to the pattern of monoclinic monazite phase. Fig. 4. displays an example of the XRD patterns recorded for the $5 \%$-doped and stoichiometric materials obtained by using two different ILs. With increasing amounts of $\mathrm{Nd}^{3+}$ ions a shifting of all diffraction peaks towards higher $2 \Theta$ angles is observed. For as-prepared with using IL2 raw materials the powder diffraction patterns show very good matching with the simulated patterns, what confirm that we obtained the monoclinic monazite phase. For IL1 the reflections are note formed well, the samples are amorphous and a clear assignment of the crystallographic structure is very difficult.

For all compounds we observe a very broad reflections characteristic for nanomaterials. From this comparison one can conclude that the synthesis with using IL2 leads to a product better crystalized and of better quality.

\subsection{Morphology and particle size by SEM and TEM analysis}

The morphologies of nano-crystallites were analyzed with using a scanning electron microscopy (SEM) and a transmission electron microscopy (TEM).

Representative micrographs of $\mathrm{LaPO}_{4}: \mathrm{Nd}^{3+}$ nanoparticles obtained by using the two ILs IL1 and IL2 are presented in Fig. 5. The left part of the figure presents the nanoparticles obtained using $\mathrm{BmPyrH}_{2} \mathrm{PO}_{4}$ (IL1), on the right side we present the results obtained when using [choline] $\mathrm{H}_{2} \mathrm{PO}_{4}$ (IL2), The overview pictures reveal the presence of nanoparticles that are loosely aggregated. Especially in the case of the product obtained from IL 1, the relatively small nanoparticles form agglomerates creating balls of dimensions of about $700 \mathrm{~nm}$ (see Fig.5 left). The large magnification by using the TEM technique reveals that in the nanoparticles obtained from IL1 most probably we observe at segregation of the $\mathrm{Nd}^{3+}$ ion in the middle of the ball seen as the white areas in the middle of the sphere. As we see from the SEM micrographs the number of such spherical agglomerates are fairly big.

For $\mathrm{Nd}^{3+}$-doped $\mathrm{LaPO}_{4}$ obtained from IL 2 [choline] $\mathrm{H}_{2} \mathrm{PO}_{4}$ (Fig. 5, right) the images are somewhat different. Both in the TEM and SEM micrographs we observe not such an extremely strong agglomeration. Separate irregularly shaped nanoblocks can be made out.

Similar morphology we have observed for the $\mathrm{Eu}^{3+}$-doped samples of $\mathrm{LaPO}_{4}$ prepared with [choline] $\mathrm{H}_{2} \mathrm{PO}_{4}$.[ 6]

The obtained results are very similar in two series of $\mathrm{Nd}^{3+}$-doped lanthanum orthophosphates contained different concentrations of the activator according to the application of the different ionic liquids. The series from IL1 clearly shows the higher 
agglomeration of the products which is in agreement with the XRD analysis, confirming that the product of better quality with using of IL2 ionic liquid was obtained.

\subsection{FT-IR spectra}

The infrared spectra recorded for both types of samples is given in Fig. 6. Most of the bands are characteristic of the vibrations of phosphate groups $\mathrm{PO}_{4}{ }^{3-}$. So the characteristics of monoclinic phase of four band, located at about 536, 563, 577 and $623 \mathrm{~cm}^{-1}$, were clearly observed in the $v_{4}$ region of $\mathrm{PO}_{4}$ group's vibration (the bending vibrations). A massive band appears in the $v_{3}$ (stretching vibrations) region between 900 and $1150 \mathrm{~cm}^{-1}$. In comparison with the hexagonal structure, the presence of additional bands of phosphate vibrations is characteristic of the vibration of phosphate groups in the monoclinic structure of monazitetype $\mathrm{LaPO}_{4}$ and results from the distortion of the tetrahedral phosphate groups in the nine-fold coordinated La atoms [23, 24].

Unexpectedly, we observe the broad bands between 3250 and $3750 \mathrm{~cm}^{-1}$ and 1250-1600 what confirm the presence of the molecules $\mathrm{H}_{2} \mathrm{O}$ on the surface. The same low temperatures synthetic method applied for $\mathrm{LaPO} 4: \mathrm{Eu}^{3+}$ gives an access to anhydrous nanophosphates with excellent photophysical properties $[6,11]$. The absence of water and hydrous compounds was confirmed by IR spectroscopy. Also for $\mathrm{GdPO}_{4}: \mathrm{Eu}^{3+}$ only the characteristic assymmetric P-O modes in the $1250-750 \mathrm{~cm}^{-1}$ spectral range were observed. The broad intense $\mathrm{O}-\mathrm{H}$ band usually located between $3350-3650 \mathrm{~cm}^{-1}$ was absent. In case of $\mathrm{YPO}_{4}: \mathrm{Eu}^{3+}$ traces of this band can be noticed. But as the intensity of observed $\mathrm{O}-\mathrm{H}$ band is relatively low it could be due to the traces of surface bond water.

Because the measurements were performed in the nujol oil, the spectrum of this oil is presented in figure also. We can clearly see that the bands located at 721, 1377, 1460, 2854 and $2938 \mathrm{~cm}^{-1}$ overlap with bands observed for the samples under investigations.

In IR spectra for the samples activated with the $\mathrm{Nd}^{3+}$ ions the intensities of characteristic $\mathrm{P}-\mathrm{O}$ modes both in the spectra range of $650-500 \mathrm{~cm}^{-1}$ and $1250-750 \mathrm{~cm}^{-1}$ are higher for the sample obtained from IL2 (choline). Also at the same time for the sample the O-H modes in the $1250-1700 \mathrm{~cm}^{-1}$ spectral region are less intense. The obtained results allow to conclude that $\mathrm{Nd}^{3+}$-doped samples have a higher affinity to keep the water on the surface than that activated with the $\mathrm{Eu}^{3+}$ ones. We should not forget that in the samples used for IR investigations the concentration of the $\mathrm{Nd}^{3+}$ ions was high $(50 \%)$ which may also be important, as introducing into the crystal lattice cations with somehow different size $\left(\mathrm{La}^{3+}\right.$ were replacing by $\mathrm{Nd}^{3+}$ ) can cause some structural distortions. However, our results confirm 
previous findings that choline dihydrogenphosphate is very efficient reactant allowing to stabilizing the obtained nanoparticles.

Investigations of the effect of $\mathrm{Nd}^{3+}$ ion concentration in $\mathrm{LaPO}_{4}$ on the presence of molecules of water with using different ionic liquids, but the same method and conditions of synthesis will be the subject of our further work. Despite a large number of articles devoted to nanocrystalline $\mathrm{LaPO}_{4}$ activated with different lanthanides and obtained by fast method the knowledge about the $\mathrm{Nd}^{3+}$-doped lanthanum orthophosphates is still very limited.

\subsection{Spectroscopic consideration}

\subsubsection{Energy level diagram of $\mathrm{Nd}^{3+}$}

The trivalent neodymium ion can be used to study the local environment structure in the host matrix.

Fig. 7 presents the energy level diagram for the $\mathrm{Nd}^{3+}$ ion with $4 \mathrm{f}^{3}$ configuration. Electronic transitions are located in a wide spectral region (V-UV, UV, NIR and IR). There are two important levels: the singlet of ${ }^{2} \mathrm{P}_{1 / 2}$ and the doublet of ${ }^{4} \mathrm{~F}_{3 / 2}$, which can be useful for structural studies. On the basis of the number of components for these transitions observed in the absorption spectra at low temperature $(4 \mathrm{~K})$ one can conclude on the number of nonequivalent positions occupied by the $\mathrm{Nd}^{3+}$ ion in the host lattice.

\subsubsection{Optical absorption spectra}

As it was discussed above powder X-ray diffraction and the electron microscopy showed the formation of a better crystallized product using IL2- [choline] $\mathrm{H}_{2} \mathrm{PO}_{4}$. For that reason, we first will describe the spectroscopic studies for this material. Fig. 8 presents the absorption spectra of sample measured at room and liquid helium temperature. The absorption spectra of monazite $\mathrm{Nd}^{3+}$-doped lanthanum orthophosphate in the visible and NIR regions involves parity forbidden $f-f$ transitions from the ${ }^{4} \mathrm{I}_{9 / 2}$ ground state to the various excited states. We clearly observe the line narrowing at low temperature what points to on ordered structure. The narrow and well separated peak that typically observed for high-symmetry systems such as $\mathrm{Nd}^{3+}$-doped YAG. It is well known that for highly symmetric systems where the $\mathrm{Nd}^{3+}$ features site symmetry such as $\mathrm{O}_{\mathrm{h}}$ and $\mathrm{D}_{4 \mathrm{~h}}$, the intensities of two transitions: the hypersensitive ${ }^{4} \mathrm{I}_{9 / 2} \rightarrow{ }^{4} \mathrm{G}_{5 / 2},{ }^{2} \mathrm{G}_{7 / 2}$ and the ${ }^{4} \mathrm{I}_{9 / 2} \rightarrow{ }^{4} \mathrm{~F}_{7 / 2},{ }^{4} \mathrm{~S}_{3 / 2},{ }^{4} \mathrm{I}_{9 / 2} \rightarrow{ }^{4} \mathrm{~F}_{5 / 2},{ }^{2} \mathrm{H}_{9 / 2}$ ones in IR region are about one half of those of the ${ }^{4} \mathrm{I}_{9 / 2} \rightarrow{ }^{4} \mathrm{G}_{5 / 2},{ }^{2} \mathrm{G}_{7 / 2}$ transition, while in low symmetry environments the ratio is significantly higher [28]. According to these rules it is possible to conclude that system under investigations exhibits quite low symmetry because the intensities of two transitions in the IR region are comparable and even higher than for the ${ }^{4} I_{9 / 2} \rightarrow{ }^{4} G_{5 / 2}$, 
${ }^{2} \mathrm{G}_{7 / 2}$. one. Moreover, according to the Judd-Jørgensen [29] statement the $f-f$ transitions which obey the $\Delta \mathrm{J}=2, \Delta \mathrm{L}=2$ selection rules are the most sensitive to the lanthanide ion environment, and are commonly referred to as hypersensitive. The $\mathrm{Nd}^{3+}{ }^{4} \mathrm{I}_{9 / 2} \rightarrow{ }^{4} \mathrm{G}_{5 / 2}$ absorption transition satisfies the above criteria, and therefore its intensity is often use as a probe for structural changes, similarly to the ${ }^{4} \mathrm{I}_{9 / 2} \rightarrow{ }^{4} \mathrm{~F}_{5 / 2}$ transition in the IR region, which also partially satisfies the selection rule for a hypersensitive transition. In practice the energy of the ${ }^{2} \mathrm{G}_{7 / 2}$ term is very close to that of the ${ }^{4} \mathrm{G}_{5 / 2}$, thus at room temperature the ${ }^{4} \mathrm{I}_{9 / 2} \rightarrow{ }^{4} \mathrm{G}_{5 / 2 \mathrm{~g}},{ }^{2} \mathrm{G}_{7 / 2}$ transitions cannot be separated and must be analyzed together. The highest intensity is observed for the hypersensitive ${ }^{4} \mathrm{I}_{9 / 2} \rightarrow{ }^{4} \mathrm{G}_{5 / 2},{ }^{2} \mathrm{G}_{7 / 2}$ transitions, due to the structural distortion of the site occupied by $\mathrm{Nd}^{3+}$. Because of the low point symmetry of the lanthanide sites and the absence of transition selection rules between the CF (crystal field) components, the maximum number of lines for each transition from the ${ }^{4} \mathrm{I}_{9 / 2}$ level is given by the $\mathrm{J}$ multiplicity of the excited level, i.e. $J+1 / 2$. One can clearly observe more than $J+1 / 2$ lines for the ${ }^{4} \mathrm{I}_{9 / 2} \rightarrow{ }^{2} \mathrm{H}_{11 / 2}$ and ${ }^{4} \mathrm{I}_{9 / 2} \rightarrow{ }^{4} \mathrm{G}_{7 / 2},{ }^{4} \mathrm{G}_{5 / 2}$ transitions. In the absorption spectra presented in Fig. 8 six well resolved lines are observed.

Since at $4 \mathrm{~K}$ only the lowest Stark component of this multiplet is populated, the number of components of the Kramer's doublet ${ }^{4} \mathrm{I}_{9 / 2} \rightarrow{ }^{2} \mathrm{P}_{1 / 2}$ transition is consisted with the number of metal sites in the crystal structure. At room temperature more than one (even four) components of the ${ }^{4} \mathrm{I}_{9 / 2} \rightarrow{ }^{2} \mathrm{P}_{1 / 2}$ transition are well observed: $i . e$. the lines line located at 428.5 $\mathrm{nm}\left(23337 \mathrm{~cm}^{-1}\right), 429.7 \mathrm{~nm}\left(23272 \mathrm{~cm}^{-1}\right), 432.4 \mathrm{~nm}\left(23127 \mathrm{~cm}^{-1}\right)$ and $434\left(23041.5 \mathrm{~cm}^{-1}\right)$. Going to the $4 \mathrm{~K}$ three lines located at $429.7 \mathrm{~nm}, 432.4 \mathrm{~nm}$ and $434 \mathrm{~nm}$ disappear what suggests that they represents the transitions from the higher energy Stark components of the ${ }^{4} \mathrm{I}_{9 / 2}$ ground state of one $\mathrm{Nd}^{3+}$ site $\left(69,210\right.$ and $296 \mathrm{~cm}^{-1}$, respectively). One line at $4 \mathrm{~K}$ for ${ }^{4} \mathrm{I}_{9 / 2}$ $\rightarrow{ }^{2} \mathrm{P}_{1 / 2}$ transition $(428.5 \mathrm{~nm})$ indicates one distribution of $\mathrm{Nd}^{3+}$ ion in investigated $\mathrm{LaPO}_{4}$.

The second very important from the structural point of view transition is the ${ }^{4} \mathrm{I}_{9 / 2} \rightarrow{ }^{4} \mathrm{~F}_{3 / 2}$ one. In this transition for one symmetry site one should observe two peaks at $4 \mathrm{~K}$. The lowtemperature absorption spectra of $\mathrm{Nd}^{3+}$-doped $\mathrm{LaPO}_{4}$ presented in Fig.8 reveals two well defined lines at $862.5 \mathrm{~nm}\left(11594 \mathrm{~cm}^{-1}\right)$ and $871 \mathrm{~nm}\left(11481 \mathrm{~cm}^{-1}\right)$ which correspond to ${ }^{4} \mathrm{I}_{9 / 2}(\mathrm{Z} 1,2) \rightarrow{ }^{4} \mathrm{~F}_{3 / 2}(\mathrm{R} 2)$ and ${ }^{4} \mathrm{I}_{9 / 2}(\mathrm{Z} 1,2) \rightarrow{ }^{4} \mathrm{~F}_{3 / 2}(\mathrm{R} 1)$ transitions, respectively. Both peaks are quite broad and not resolved. Based on these results one can suggest again the presence of one main distribution of the $\mathrm{Nd}^{3+}$ ion in this structure and so confirm the previous assignment. 
Different results we observe in the case of compounds using $\mathrm{BmPyrH}_{2} \mathrm{PO}_{4}$ (1IL) (see Fig. 9). For the ${ }^{4} \mathrm{I}_{9 / 2} \rightarrow{ }^{2} \mathrm{P}_{1 / 2}$ transition at room temperature a very broad band with a maximum at $429 \mathrm{~nm}$ a much weaker transition at $432 \mathrm{~nm}$ have been observed. At 4K event 4 bands become apparent: $427.5 \mathrm{~nm}\left(23392 \mathrm{~cm}^{-1}\right), 429 \mathrm{~nm}(23310$ $\left.\mathrm{cm}^{-1}\right), 430 \mathrm{~nm}\left(23256 \mathrm{~cm}^{-1}\right)$ and $432 \mathrm{~nm}\left(23148 \mathrm{~cm}^{-1}\right)$. Based on this observation one can conclude the presence more than one $\mathrm{Nd}^{3+}$ site in the material with a huge disorder in the structure. The confirmation of multisite character in the sample we can find in the spectra from the 840-890 nm spectral region presenting the ${ }^{4} \mathrm{I}_{9 / 2} \rightarrow{ }^{4} \mathrm{~F}_{3 / 2}$ transition. Here at room temperature two broad lines with maxima at 86 and $870 \mathrm{~nm}$ are present which correspond to ${ }^{4} \mathrm{I}_{9 / 2}(\mathrm{Z} 1,2) \rightarrow{ }^{4} \mathrm{~F}_{3 / 2}(\mathrm{R} 2)$ and ${ }^{4} \mathrm{I}_{9 / 2}(\mathrm{Z} 1,2) \rightarrow{ }^{4} \mathrm{~F}_{3 / 2}(\mathrm{R} 1)$ transitions, respectively. At liquid helium temperature two additional bands at 864.5 and $881.5 \mathrm{~nm}$ occurred..

This disorder of the active ions in the structure in this sample manifests also very well for other transitions what is clearly seen on the overview absorption spectra recorded at room and low temperature in the $200-900 \mathrm{~nm}$ spectral range. The bands in the room-temperature absorption spectra are relatively broad. Going to liquid helium temperature due to the depopulation of the crystal field components of the ${ }^{4} \mathrm{I}_{9 / 2}$ ground state multiplet, all the bands occurring in the absorption spectra become slightly narrower. However, even at low temperature the splitting of the bands is not as good as it was observed for $\mathrm{Nd}^{3+}$-doped $\mathrm{LaPO}_{4}$ obtained with using the IL2- [choline $] \mathrm{H}_{2} \mathrm{PO}_{4}$ precursor.

\subsection{Luminescence spectra}

Fig. 10 shows the room and low $(77 \mathrm{~K})$ temperature emission spectra recorded under excitation with an $\mathrm{Ar}^{+}$laser $\left(\lambda_{\mathrm{ex}}=514 \mathrm{~nm}\right)$ for $\mathrm{LaPO}_{4}$ activated with $5 \mathrm{~mol} \% \mathrm{Nd}^{3+}$ prepared from both ILs. The emission spectra of diluted neodymium lanthanum orthophosphates can also be used to check the structure of the metal center in this matrix. The effective phonon energy of phosphates is around $1075 \mathrm{~cm}^{-1}$, so the ${ }^{4} \mathrm{~F}_{3 / 2}$ level of $\mathrm{Nd}^{3+}$ ion in this compound should relax by radiative transition. As in case of the absorption measurements the better results were obtained for the sample from IL2 precursor. The high resolution emission spectra exhibit the lines originating from the ${ }^{4} \mathrm{~F}_{3 / 2} \rightarrow{ }^{4} \mathrm{~F}_{9 / 2}$ transition. It is well known from the group theory consideration that the ${ }^{4} \mathrm{~F}_{3 / 2}$ multiplet splits into two Kramer's doublets and the number of components correlates with $J+1 / 2$ levels for one site. In the band corresponding to the ${ }^{4} \mathrm{~F}_{3 / 2} \rightarrow{ }^{4} \mathrm{I}_{9 / 2}$ transition $(\lambda \sim 900 \mathrm{~nm})$ we can distinguish more than five lines (the number predicted by the complete lifting of the degeneracy of the ${ }^{4} \mathrm{I}_{9 / 2}$ level). For the IL2 precursors we observe well separated lines with the same number (7 components) both at room 
temperature as well as at $77 \mathrm{~K}$. Then, the two lines at highest energy (shortest wavelength 863 and $868 \mathrm{~nm}$ ) are corresponding to emission transition coming from the R2 levels which is still populated at $77 \mathrm{~K}$.

In the emission spectra presented in Fig. 10 we can see a significant difference in the shape of the spectrum and the amount of components for the nanomaterial from IL1 precursor, what confirm the inhomogeneity of the sample and multisite character. In contrary of the IL2 sample one can well distinguish 10 lines which are not attributed to the R2 population but to a second kind of site distribution. In addition the intensity of the emission from the sample from IL2 is about ten times stronger than from IL1 (in the spectrum presented in the Fig 10 the slits for the IL2 were much smaller than for IL1).

Fig. 11 shows the low temperature emission spectra for diluted samples obtained from both precursors under excitation in ${ }^{4} \mathrm{G}_{5 / 2},{ }^{2} \mathrm{G}_{7 / 2}$ multiplet with using a non-selective excitation source: a LED at $590 \mathrm{~nm}$. As under $\mathrm{Ar}^{+}$line excitation, the samples prepared from the IL2 show stronger emission from the ${ }^{4} \mathrm{~F}_{3 / 2}$ level to the three: ${ }^{4} \mathrm{I}_{9 / 2} \quad(850-955 \mathrm{~nm})$, ${ }^{4} \mathrm{I}_{11 / 2}(1045-1080 \mathrm{~nm})$ and ${ }^{4} \mathrm{I}_{13 / 2}(1300-1450 \mathrm{~nm})$ terms of ${ }^{4} \mathrm{I}_{\mathrm{J}}$ multiplet. We clearly see the differences for both type of analyzed compounds: for instance, in the second range, the most intense lines are observed at shorter or longer wavelength than $1065 \mathrm{~nm}$ for IL1 and IL2 respectively.

In Fig. 12 we present also the emission spectra for the stoichiometric sample $\left(\mathrm{NdPO}_{4}\right)$ from IL2 precursor recorded at room temperature and 77K under $805 \mathrm{~nm}$ excitation. Analogous spectra than lower concentrated sample are obtained especially at low temperature with no drastic broadening effect proving a good homogeneity of this choline compound.

\subsection{Luminescence decays}

The luminescence decay profiles of fluorescence from the ${ }^{4} \mathrm{~F}_{3 / 2}$ metastable state (monitored at $1060 \mathrm{~nm}$ ) for both types of $\mathrm{LaPO}_{4}: \mathrm{Nd}^{3+}$ materials (IL1 and IL2) with different concentrations of $\mathrm{Nd}^{3+}$ ion recorded at room temperature and $77 \mathrm{~K}$ are presented in Figs 13a and $\mathrm{b}$. The decay curves were measured under pulsed $\lambda_{\mathrm{ex}}=581 \mathrm{~nm}$ of OPO laser excitation in the hypersensitive ${ }^{4} \mathrm{I}_{9 / 2} \rightarrow{ }^{4} \mathrm{G}_{5 / 2},{ }^{2} \mathrm{G}_{7 / 2}$ transitions.

For the samples obtained using IL1 the decay time $\tau$ are very similar whatever the concentration does not experience a significant lengthening as temperature is lowered to $77 \mathrm{~K}$ with a fast decay time of about $150 \mathrm{~ns}$, which should be due to energy transfer and the slowest radiative neodymium emission of few microseconds. Such a lack of thermal dependence due to the presence of the high-energy stretching vibrational modes of the $\mathrm{H}_{2} \mathrm{O}$ molecule as clearly shown in the IR spectra displayed in Fig. 6. Most probably, the fast decay times of the 
${ }^{4} \mathrm{~F}_{3 / 2}$ fluorescence measured in these materials originate from the coupling of the $\mathrm{Nd}^{3+}$ excited states to the vibrational modes of the water molecules located on the surface of powder. Similar values of decay times around $120 \mathrm{~ns}$ were observed in the concentrated $\mathrm{La}_{1-\mathrm{x}} \mathrm{Nd}_{\mathrm{x}} \mathrm{P}_{3} \mathrm{O}_{9} * 3 \mathrm{H}_{2} \mathrm{O}$ cyclotriphosphates [30] which is about three orders of magnitude lower than those measured in concentrated anhydrous metaphosphates materials [20].

Longer luminescence lifetimes can be observe for the samples obtained from IL2, what confirm that the product obtain with choline ionic liquid is well crystalized and possess less water molecules on the surface of the powder, in accordance with the IR spectra (Fig.6). Here also decay curves are non-exponential with a lifetime at $\mathrm{I}_{0} / \mathrm{e}$ of about $1.4 \mu$ s and integrated lifetime of $2.8 \mu \mathrm{s}$ for $10 \mathrm{~mol} \%$ of $\mathrm{Nd}^{3+}$ and about $1 \mu \mathrm{s}$ and $2.0 \mu$ s respectively for the concentration $15 \%$. In low temperature decay times slightly elongate for $10 \%$ of $\mathrm{Nd}^{3+}(1.5 \mu \mathrm{s}$ at $\mathrm{RT}$ and $1.4 \mu \mathrm{s}$ at $77 \mathrm{~K})$ and for $15 \%$ of $\mathrm{Nd}^{3+}(1.0 \mu \mathrm{s}$ at $\mathrm{RT}$ and $1.1 \mu \mathrm{s}$ at $77 \mathrm{~K})$. Fluorescence quenching is pointing out for the highest concentration ( $50 \mathrm{~mol} \%$ of $\mathrm{Nd}^{3+}$ ions $\tau=0.6 \mu \mathrm{s}$ ) due to energy transfer by self-trapping process between the optically active $\mathrm{Nd}^{3+}$ ions and also by usual up/down conversion and cross-relaxation mechanisms due to the great numbers of resonances between $\mathrm{Nd}^{3+}$ levels. For the sample contained of $50 \mathrm{~mol} \%$ of $\mathrm{Nd}^{3+}$ decay curve follows a single exponential decay, even in the presence of energy transfer processes. This exponential decay of the $\mathrm{Nd}^{3+}$ (donor ions, in this case) fluorescence in presence of energy transfer is characteristic of migration assisted energy transfer processes [31,32].

For the $\mathrm{Nd}^{3+}$ stoichiometric crystal $\left(\mathrm{NdPO}_{4}\right)$ the average distance between adjacent $\mathrm{Nd}^{3+}$ ions is relatively small (of the order of $4 \AA$ ), leading to an efficient donor-donor interaction and decay times of $\mathrm{Nd}^{3+}$ fluorescence from the ${ }^{4} \mathrm{~F}_{3 / 2}$ metastable state (monitored at $880 \mathrm{~nm}$ ) are equal to 1.7 at RT and $2.6 \mu$ s at $15 \mathrm{~K}$ [33]. These results obtained for the stoichiometric single crystal do not differ dramatically from our values obtained for the $\mathrm{Nd}: \mathrm{LaPO}_{4}$ nanoparticules prepared with using choline IL. The first reason of quenching process is probably $\mathrm{OH}$ group after energy transfer $\mathrm{Nd}-\mathrm{OH}$. In addition these $\mathrm{OH}$ groups create defects within the lattice and then some inhomogeneities.

At this point, it is worth noting that the relatively short value of the $\mathrm{Nd}^{3+}{ }^{4} \mathrm{~F}_{3 / 2}$ fluorescence decay time in $\mathrm{LaPO}_{4}: \mathrm{Nd}^{3+}$ (IL2) should lead to a very weak fluorescence intensity, a fact which is not reflected in our experiments.

The obtained results stay in a good agreement with others results obtained for both series of compounds and confirm that grain size, quality and homogeneity of samples play very 
important role on the decays and luminescence quenching processes occurring in the series of samples under investigation.

Very important from the point of view the fluorescence quenching problem in the $\mathrm{Nd}^{3+}$ doped nanophosphates is research performed by Samsonova for $\mathrm{Nd}^{3+}: \mathrm{YPO}_{4}$ nanoparticles where she applied the energy transfer probing based on the analysis of kinetics of impurity quenching to determine the presence and spatial position of $-\mathrm{OH}$ fluorescence quenching acceptors in the impurity-containing nanoparticles present. The authors claim that the impurity quenching kinetics of the 0.1 at $\% \mathrm{Nd}^{3+}$ doped $\mathrm{YPO}_{4}$ nanoparticles is a two stage (ordered and disordered) static kinetics, determined by a direct energy transfer to the $-\mathrm{OH}$ acceptors. Analyzing the ordered stage, they assumed that the origin of the $-\mathrm{OH}$ groups is the protonation of the phosphate groups, while analyzing the disordered stage, they assumed the presence of water molecules in the mesopores. As the main result they have established that the majority of $-\mathrm{OH}$ acceptors is located not on the surface of the $\mathrm{Nd}^{3+}: \mathrm{YPO}_{4}$ nanoparticles, as many researchers assumed, but in their volume, and can be either associated with crystal structure defects or located in the mesopores [22].

As it was reported earlier using the [choline $] \mathrm{H}_{2} \mathrm{PO}_{4}$ ionic liquid as a reactant and in-situ stabilizer led to obtained $\mathrm{LnPO}_{4}: \mathrm{Eu}^{3+}$ nanoparticles with very well luminescent performance and relatively long decay times without any need for post reaction heat treatment [6].

\section{Conclusions}

Two series of nano-crystalline $\mathrm{Nd}^{3+}$-doped $\mathrm{LaPO}_{4}$ and stoichiometric $\mathrm{NdPO}_{4}$ were obtained by microwave treatment of simple lanthanide precursors such as $\mathrm{Ln}(\mathrm{OAc}) 3 \bullet x \mathrm{H} 2 \mathrm{O}$, $\mathrm{OAc}=$ acetate) with the task-specific dihydrogen phosphate ILs of $\mathrm{BmPyrH}_{2} \mathrm{PO}_{4}$ (IL1) and [choline] $\mathrm{H}_{2} \mathrm{PO}_{4}$ (IL2). Fine analysis performed by using X-ray powder diffraction confirmed formation of the pure monoclinic high-temperature monazite phase with space group $P 2_{1} / \mathrm{n}$.

For all as-prepared raw materials the powder diffraction patterns show very broad reflections which are characteristic for nanomaterials. The microwave assisted conversion of simple lanthanide precursors in task-specific ionic leads to formation of this high-temperature variety of phosphates in the form of nano-crystallites directly from the process even at low temperatures $\left(\mathrm{T}=140^{\circ} \mathrm{C} / 10 \mathrm{~min}\right)$ without the need for a post reaction heat treatment. However, the synthesis using $\mathrm{BmPyrH}_{2} \mathrm{PO}_{4}$ (IL1) leads to creation more amorphous materials than from [choline] $\mathrm{H}_{2} \mathrm{PO}_{4}$ (IL2). Also the morphology analysis performed by using SEM and TEM microscopes shows more homogeneous nanoparticles from [choline] $\mathrm{H}_{2} \mathrm{PO}_{4}$ (IL2). Analysis of the spectra of the neodymium orthophosphates synthesized with using two ILs 
points to strong differences both in the structure of these two types of phosphates, as well as the symmetries of the neodymium centers in those structures.

The absorption spectra recorded at room temperature and at $4 \mathrm{~K}$ show that the samples obtained by using [choline] $\mathrm{H}_{2} \mathrm{PO}_{4}$ (IL2) are indicative of a big arrangement in the network and most probably one symmetry site of $\mathrm{Nd}^{3+}$, however with quite low point symmetry. The samples obtained from $\mathrm{BmPyrH}_{2} \mathrm{PO}_{4}$ (IL1) show a very large degree of structural disorder with inhomogeneity and multisite character of the lanthanide ion. The ${ }^{4} \mathrm{I}_{9 / 2} \rightarrow{ }^{2} \mathrm{P}_{1 / 2}$ transition shows an unexpected high number of components (four instead of one, expected for this symmetry). The symmetry of the compounds from the synthesis with IL1 seems to be slightly higher than for IL2.

The emission spectra present a huge difference in the shape of the spectrum and the amount of components for the nanomaterial obtained from IL1 precursor and IL2, what confirm the huge inhomogeneity of the sample from IL1 and multisite character. The lanthanum orthophosphates obtained by using IL2 have shown a stronger emission. Those compounds present also longer luminescence lifetime, decay curves are nonexponential with of about $1.5 \mu$ s while for IL1 the time constant at $\mathrm{I}_{0} / \mathrm{e}$ are order of about 150 ns. Our research has demonstrated that the [choline] $\mathrm{H}_{2} \mathrm{PO}_{4}$ (IL2) is good media for fast low temperature synthesis of nanoparticuled $\mathrm{Nd}^{3+}$-doped $\mathrm{LaPO}_{4}$ than the $\mathrm{BmPyrH}_{2} \mathrm{PO}_{4}$ (IL1). The particles obtained by this way have a good performance as phosphors and even they are not $\mathrm{H}_{2} \mathrm{O} / \mathrm{OH}$ completely free the nanoparticules of $\mathrm{Nd}: \mathrm{LaPO}_{4}$ obtained from IL2 present the excellent optical properties with efficient emission in infrared spectral range. Well resolved absorption and emission spectra allow for good definition of the structure. These results stay in good agreement with the previous investigations preformed for the $\mathrm{Eu}^{3+}: \mathrm{LaPO}_{4}$ which have proved that [choline] $\mathrm{H}_{2} \mathrm{PO}_{4}$ is a very good media to obtain the well crystalized good quality nanoparticles in the low temperature fast way. In case of IL1 the predominant role in the fluorescence quenching played by the water molecules in the $\mathrm{Nd}^{3+}$ luminescence in $\mathrm{LaPO}_{4}$ was established. The quenching may be caused by vibrations of the $-\mathrm{OH}$ groups located in the volume of NPs and Nd-Nd energy migration with subsequent quenching caused by vibrations of the $-\mathrm{OH}$ groups.

Summarizing the photoluminescence investigations one can conclude that using very fast and low temperature $\left(\mathrm{T}=140^{\circ} \mathrm{C} / 10 \mathrm{~min}\right)$ synthesis route described in this paper we are able to produce good quality luminophor operating in NIR range however only [choline] $\mathrm{H}_{2} \mathrm{PO}_{4}$ (IL2) precursor should be used. Other ionic liquid of - $\mathrm{BmPyrH}_{2} \mathrm{PO}_{4}$ (1IL) with keeping exactly the same conditions of synthesis leads to an inhomogeneous material. 
Deeper investigations in the properties of this fluorescent emission will be of interest of our future research.

\section{Acknowledgments}

Joanna Cybinska and Malgorzata Guzik would like to express their gratitude to professor Georges Boulon for His support and years of very fruitful collaboration and friendship. We wish to thank the Minister of Science and Higher Education (Poland) for the grant \#POIG.01.01.02-02-006/09. This financial supports is gratefully acknowledged. The authors express the gratitude to Dr Łukasz Marciniak from Institute of Low Temperature and Structure Research of Polish Academy of Science in Wroclaw for some help in measurements of luminescence. This work is supported in part by the Critical Materials Institute, an Energy Innovation Hub funded by the U.S. Department of Energy, Office of Energy Efficiency and Renewable Energy, Advanced Manufacturing Office.

\section{References}

1. X. Duan, J. Ma, J. Lianc, W. Zheng, Cryst Eng Comm, 16 (2014) 2550.

2. G.A. Ozin; A.C. Arsenault; Cardematiri, L.: Nanochemistry - A Chemical Approach to Nanomaterials, RSC Publishing, Oxford, 2009.

3. G. Schmid, ed., Nanoparticles: From Theory to Application, Wiley-VCH, Weinheim, 2004; D. Vollath: Nanomaterials: An Introduction to Synthesis, Properties and Applications, Wiley VCH, Weinheim, 2008.

4. C. Feldmann, H. Goesmann, Angew. Chem. Int. Ed. 49 (2010) 2.

5. L. Cademartiri, G. A. Ozin, J.-M. Lehn: Concepts of Nanochemistry, Wiley-VCH, Weinheim, 2009.

6. J. Cybinska, C. Lorbeer, E. Zych, A.-V. Mudring, ChemSusChem, 4 (2011) 595.

7. C. Lorbeer, J. Cybinska, A.-V. Mudring, Chem. Comm., 46 (2010) 571.

8. C. Lorbeer, J. Cybinska, A.-V. Mudring, Cryst. Growth Des., 11 (2011) 1040.

9. J. Cybinska, C. Lorbeer, A.V. Mudring, J. Mater. Chem., 22 (2012) 9505.

10. T. Alammar, J. Cybińska, P. S. Campbell, A.-V. Mudring, J. Lumin., 169 (2016) 587.

11. J. Cybinska, C. Lorbeer, A.V. Mudring, J. Lumin., 170 (2016) 641.

12. J. Legendziewicz, M. Guzik, J. Cybinska, A. Stefan, V. Lupei, Opt. Mater. 30 (2008) 1667.

13. J. Legendziewicz, M. Guzik, J. Cybinska, Opt. Mater. 31 (2009) 567. 
14. J. Legendziewicz, J. Cybińska, M. Guzik, G. Boulon., G. Meyer G, Opt. Mater., 30 (2008) 1655.

15. W. Szuszkiewicz, B. Keller, M. Guzik, T. Aitasalo , J. Niittykoski , J. Hölsä , J. Legendziewicz, J. Alloys Compd., 341 (2002) 297.

16. D. Wisniewski, S. Tavernier, A.J. Wojtowicz, M. Wisniewska, P. Bruyndonck, P. Dorenbos, E. van Loef, C.W.E. van Eijk, L.A. Boatner, Nuclear Instruments and Methods in Physics Research A 486 (2002) 239.

17. H.P. Weber, T.C. Dammen, H.G. Danielmeyer, B.C. Tofield, Appl. Phys. Lett. 22 (1973) 534.

18. H.P. Weber, Opt. QuantumElectron.7 (1975) 431.

19. H.G. Danielmeyer, Advancesin Solid State Physics, Pergamon, New York (1975) 253.

20. T. Yamada, K. Otsuka, J. Nakano, J.Appl.Phys.45 (1974) 5097.

21. M. Malinowski, W. Strek, J. Phys. C 20 (1987) 2595.

22. E. V. Samsonova, A. V. Popov, A. S. Vanetsev, K. Keevend, E. O. Orlovskaya, V. Kiisk, S. Lange, U. Joost, K. Kaldvee, U. Maeorg, N. A. Glushkov, A. V. Ryabova, I. Sildos, V.V. Osiko, R. Steiner, V. B. Loschenov, Y.V. Orlovskii, Phys. Chem. Chem. Phys., 16 (2014) 26806.

23. M. Ferhi, K. Horchani-Naifer, M. Ferid, J. Lumin., 128 (2008) 1777.

24. M. Ferhi, K. Horchani-Naifer, M. Ferid, J. Rare Earths 27 (2009) 182.

25. A. Mesbah, N. Clavier, E. Elkaim, C. Gausse, I. B. Kacem, S. Szenknect, N. Dacheux, Cryst. Growth Des., 14 (10) (2014) 5090.

26. Y.-X. Ni, J.M. Hughes, A.N. Mariano, Am. Min., 80 (1995) 21.

27. H. Assaaoudi, A. Ennaciri, A. Rulmont, M. Harcharras, Phase Transition 72 (2000) 1.

28. J. Legendziewicz, Acta Phys. Pol. 90 (1996) 127.

29. C.K. Jørgensen, B.R. Judd, Mol. Phys. 8 (1964) 281.

30. A. Jouini, J.C. Gacon, A. Brenier, M. Ferid, M. Trabelsi-Ayadi, J. Lumin. 99 (2002) 365.

31. M.O. Ramirez, D. Jaque, L.E. Bausa, I.R. Martı'n, F. Lahoz, E. Cavalli, A. Speghini, M. Bettinelli, J. Appl. Phys. 97 (2005) 093510.

32. A. Braud, S. Girad, J.L. Doualan, M. Thuau, R. Moncorge, A.M. Tkachuk, Phys. Rev. B 61 (2000) 5280.

33. A. Rodenas, D. Jaque, J. Garcıa Sole, A. Speghini, M. Bettinelli, E. Cavalli, Optical Materials 28 (2006) 1280.

34. L. Yu, H. Liu, J. Nanomater. 46 (2010) 1309. 
Figures<smiles>CCCC[n+]1ccccc1</smiles>

IL1- BmPyrH ${ }_{2} \mathrm{PO}_{4}$<smiles>O=P([O-])(O)O</smiles>

IL2-[choline $] \mathrm{H}_{2} \mathrm{PO}_{4}$

IL1 - 1-Butyl-1-methylpyrrolidinium dihydrogenphosphate

IL2 - 2-hydroxyethyl-N,N,N-trimethylammonium dihydrogenphosphate

Fig. $1 \mathrm{ILs}\left(1 \mathrm{IL}-\mathrm{BmPyrH}_{2} \mathrm{PO}_{4}\right.$ and IL2-[choline $\left.] \mathrm{H}_{2} \mathrm{PO}_{4}\right)$ used to synthesis of nano-particuled $\mathrm{LaPO}_{4}: \mathrm{Nd}^{3+}$.

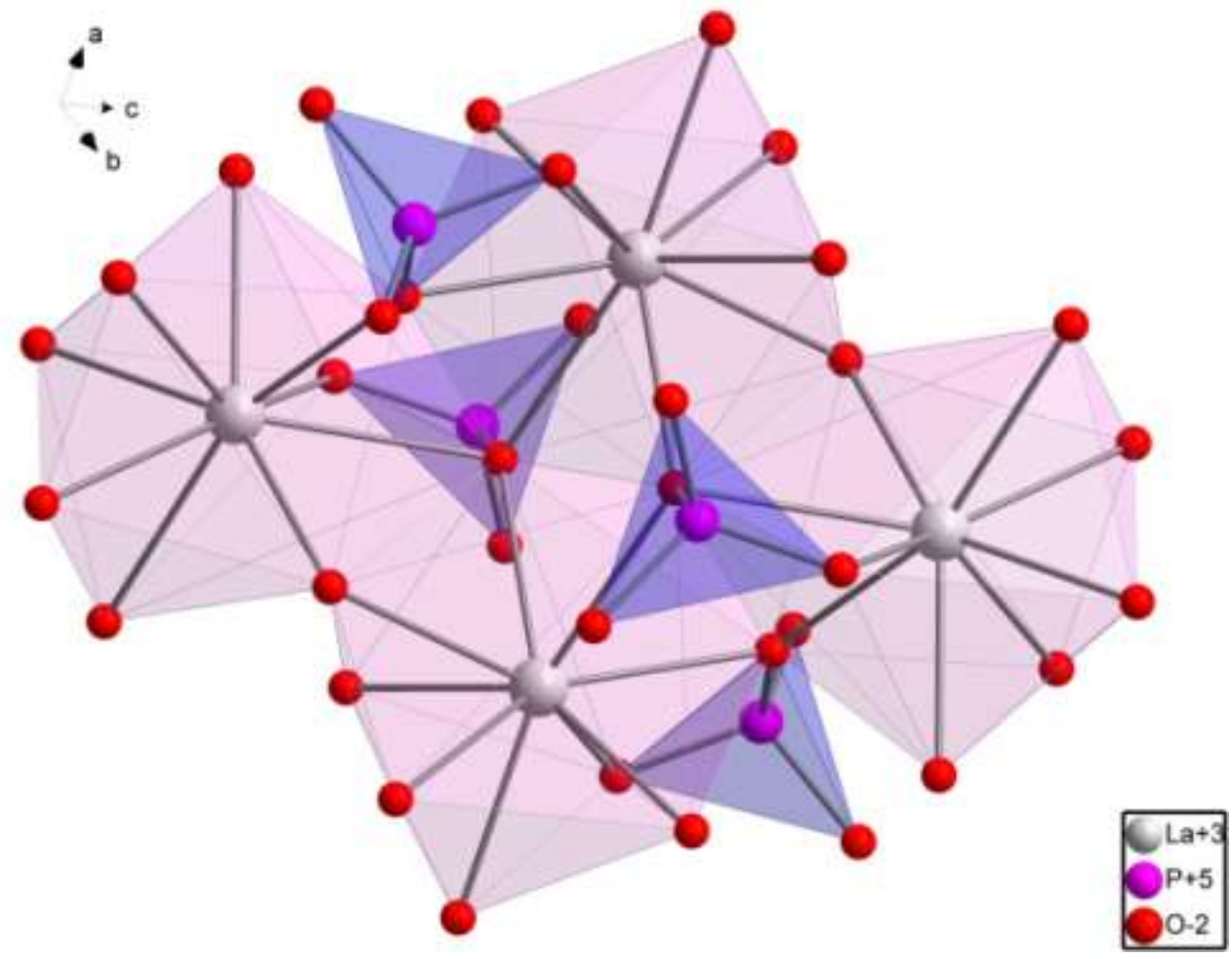



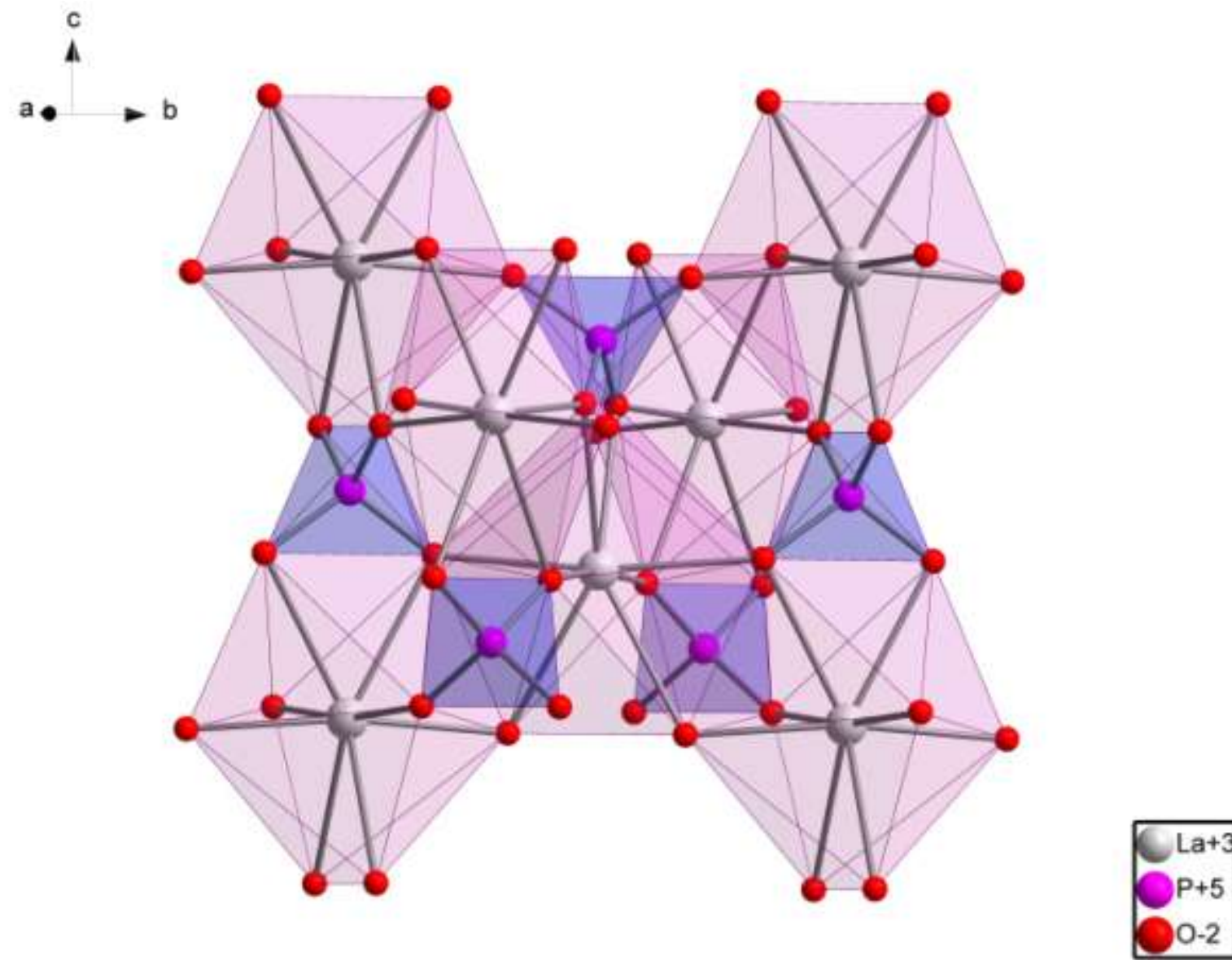

Fig. 2 View of polyhedral connection of $\mathrm{LaO}_{9}$ and $\mathrm{PO}_{4}$ tetrahedra in the structure of monoclinic $\mathrm{LaPO}_{4}$ (top) and polyhedral connection of $\mathrm{LaO}_{8}$ and $\mathrm{PO}_{4}$ tetrahedra in the structure of hexagonal $\mathrm{LaPO}_{4}$ (bottom). 


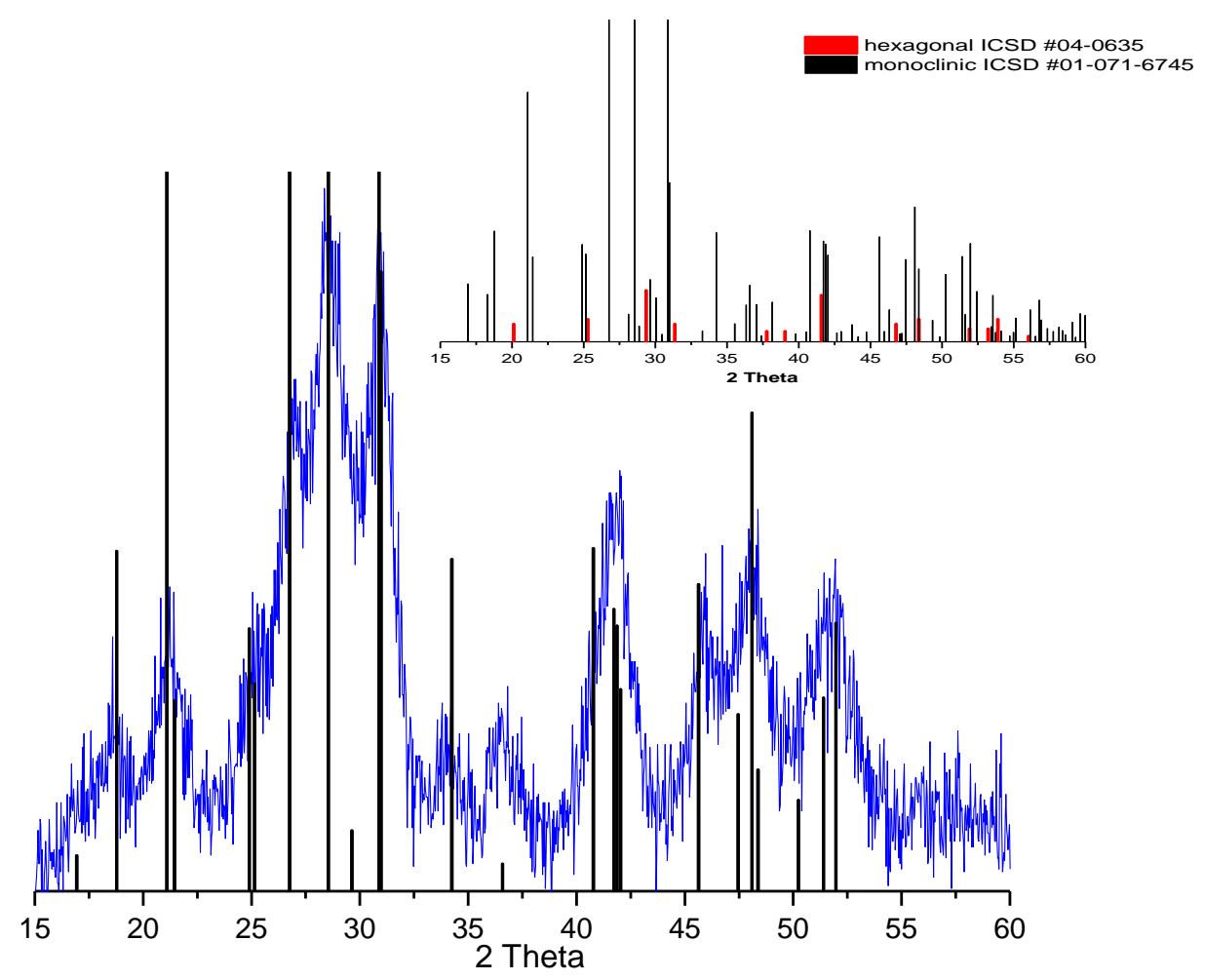

Fig.3 X-ray powder diffraction of $\mathrm{Nd}^{3+}$-doped $\mathrm{LaPO}_{4}$ (IL2) and simulated XRD patterns of monoclinic $\mathrm{LaPO}_{4}$ (ICSD\#01-071-6745). The insert contains the simulated from the Database of Inorganic Crystal Structure XRD pattern of monoclinic and hexagonal forms.

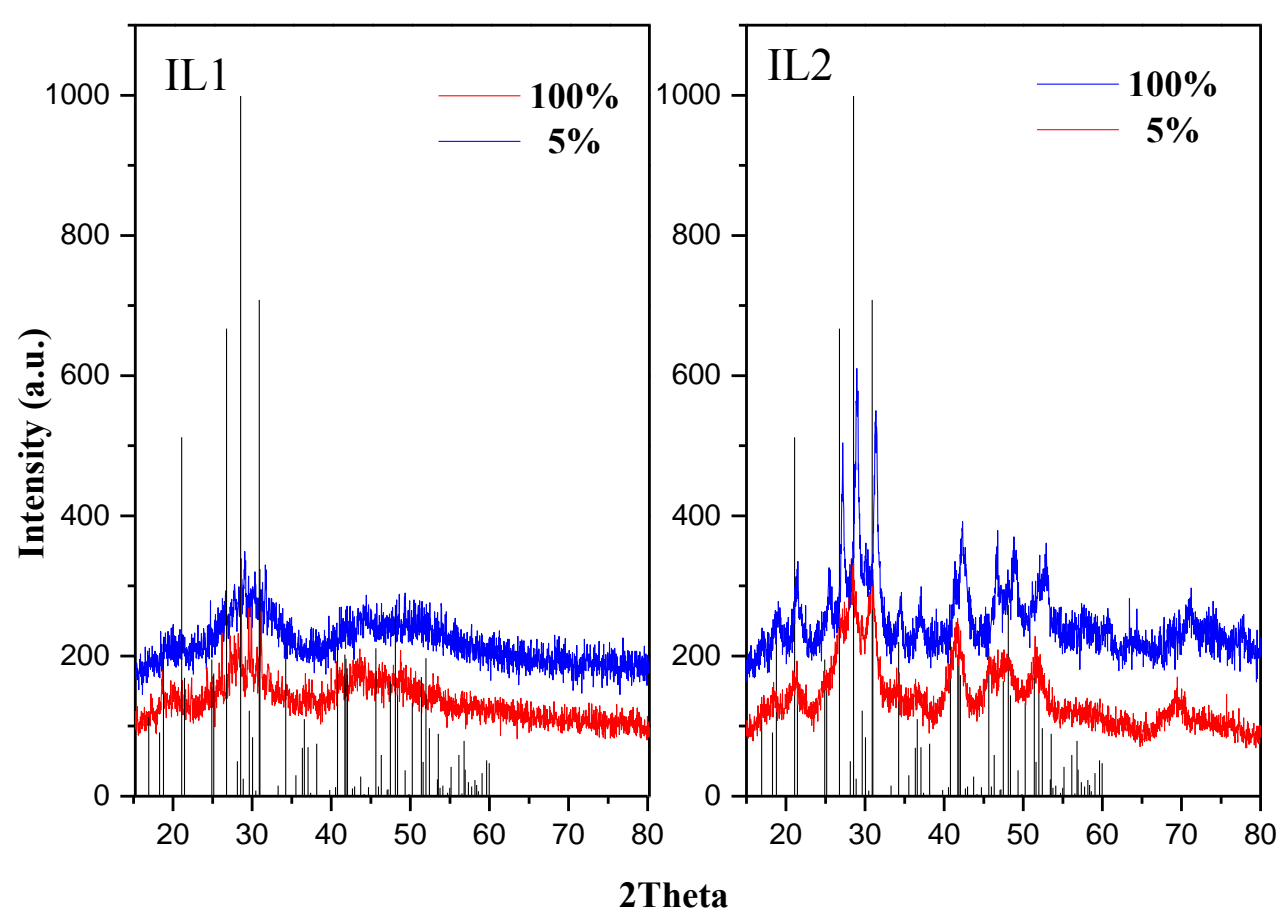

Fig.4 X-ray powder diffraction of $\mathrm{Nd}^{3+}$-doped $\mathrm{LaPO}_{4}$ and simulated XRD patterns of monoclinic $\mathrm{LaPO}_{4}(\mathrm{ICSD \# 01-071-6745)}$ and XRD patterns for the samples doped with different concentration of $\mathrm{Nd}^{3+}$ obtained by using IL1 and IL2 as reaction media. 
IL1- BmPyrH $\mathrm{PO}_{4}$

\section{IL2-[choline $\left.] \mathrm{H}_{2} \mathrm{PO}_{4}\right]$}

\section{TEM}
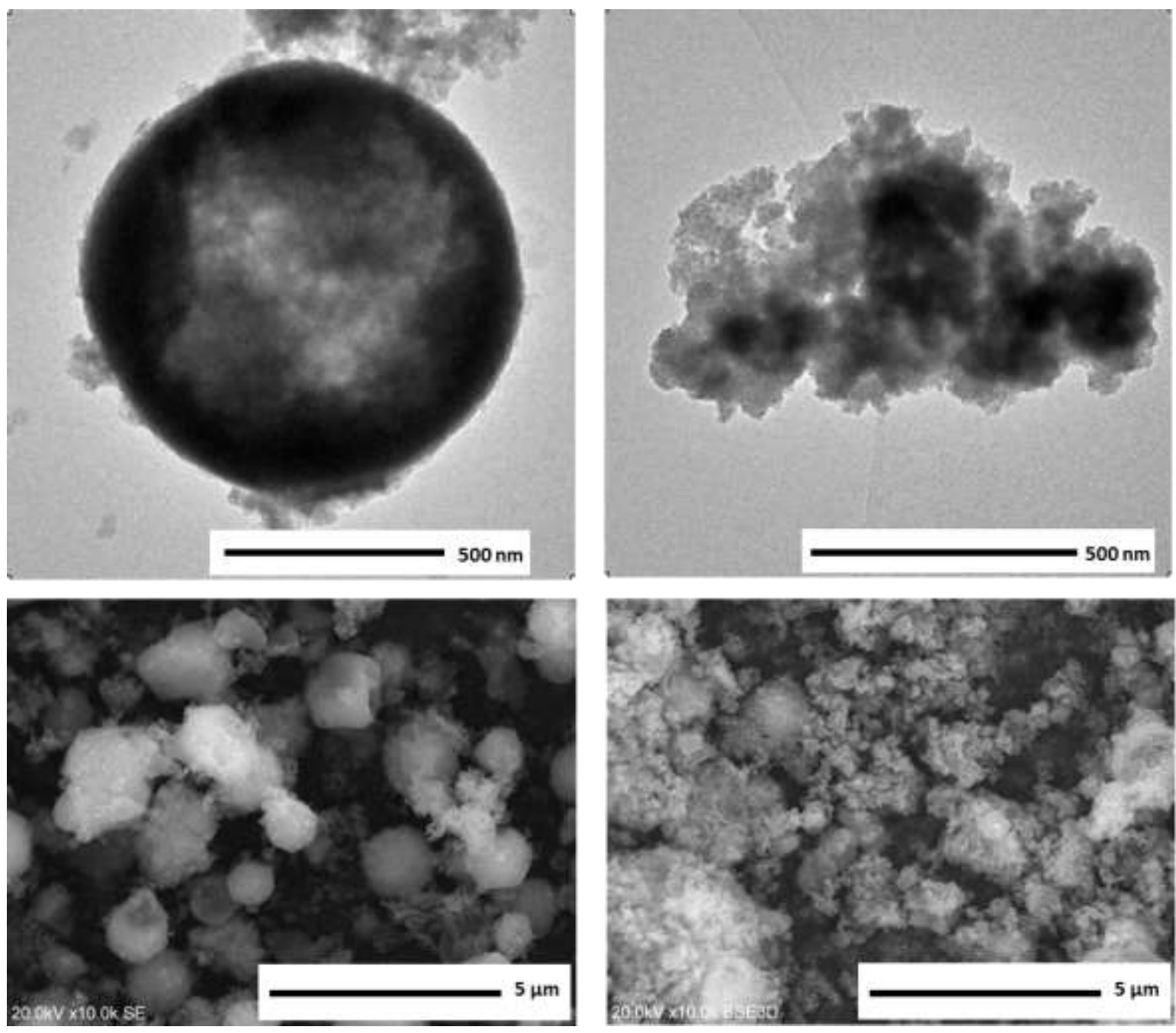

SEM

Fig.5 Representative TEM (up) and SEM (down) micrographs of $\mathrm{LaPO}_{4}: \mathrm{Nd}^{3+}$ nanoparticles obtained by using two ILs (IL1 (left) and IL2 (right)). 


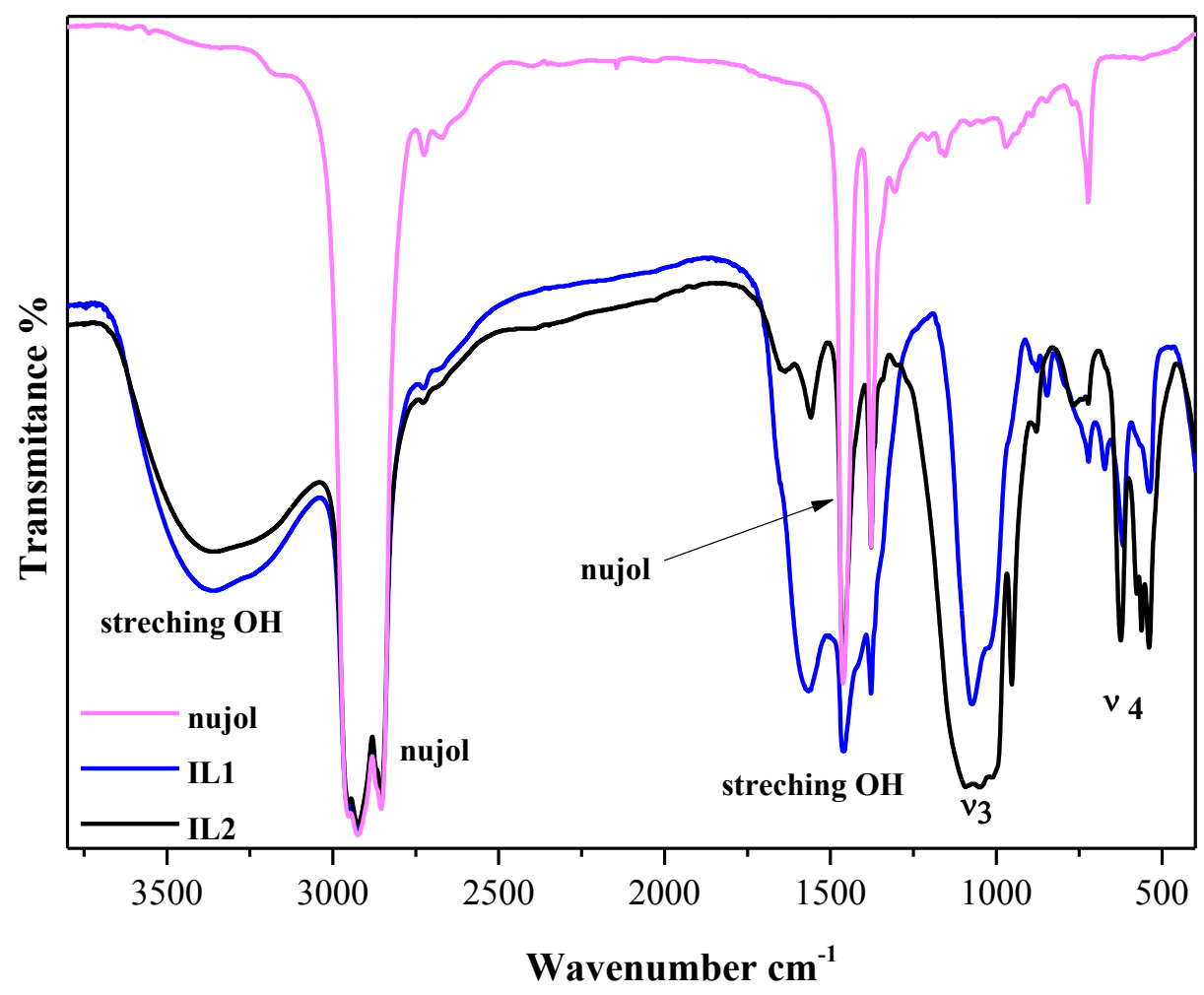

Fig.6 IR spectrum of $\mathrm{LaPO}_{4}: \mathrm{Nd}^{3+} 50 \%$ obtained with IL1 and IL2. 


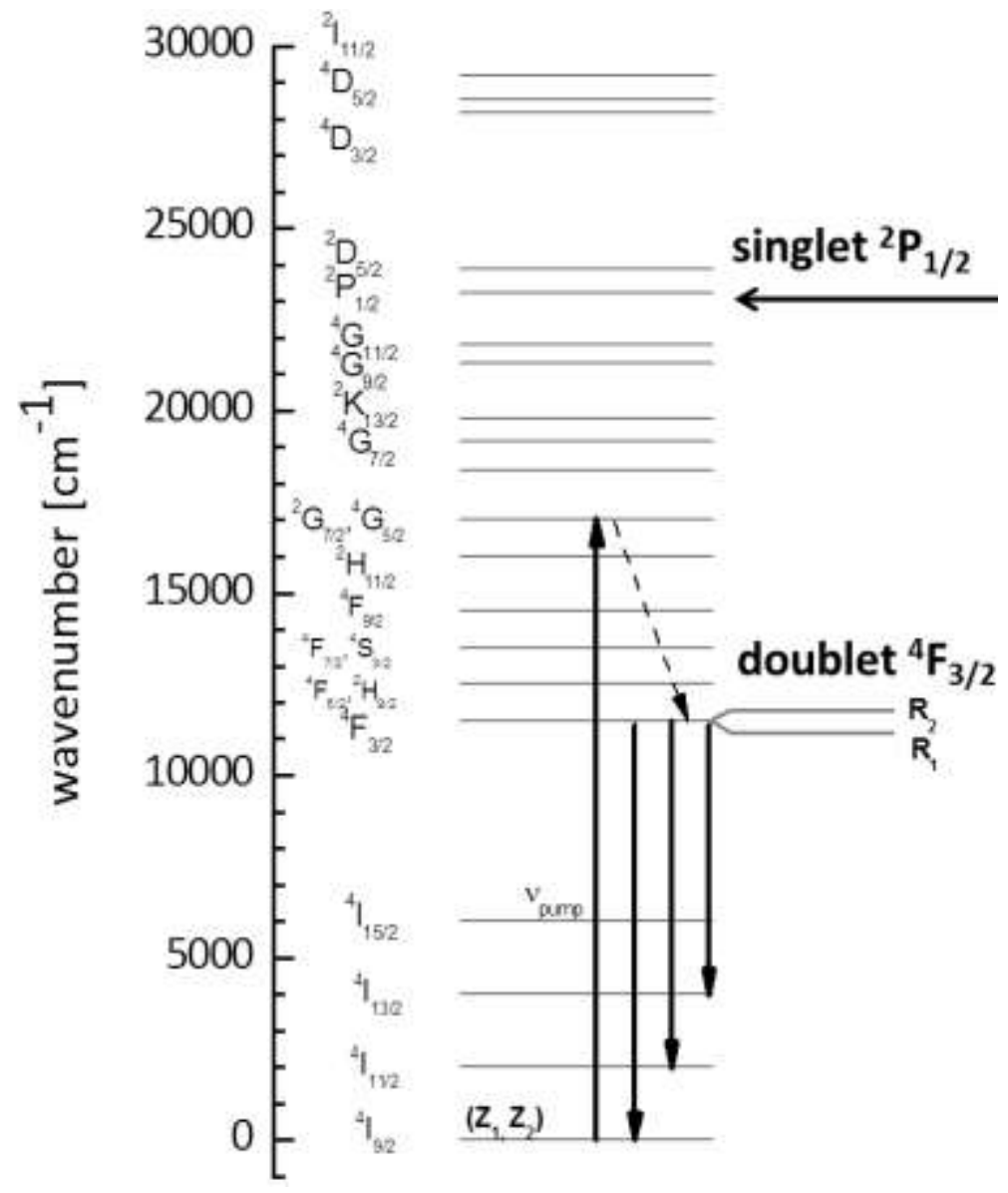

Fig.7 Energy level scheme of the $\mathrm{Nd}^{3+}$ ion with marked special levels $\left({ }^{2} \mathrm{P}_{1 / 2}\right.$ and $\left.{ }^{4} \mathrm{~F}_{3 / 2}\right)$. 


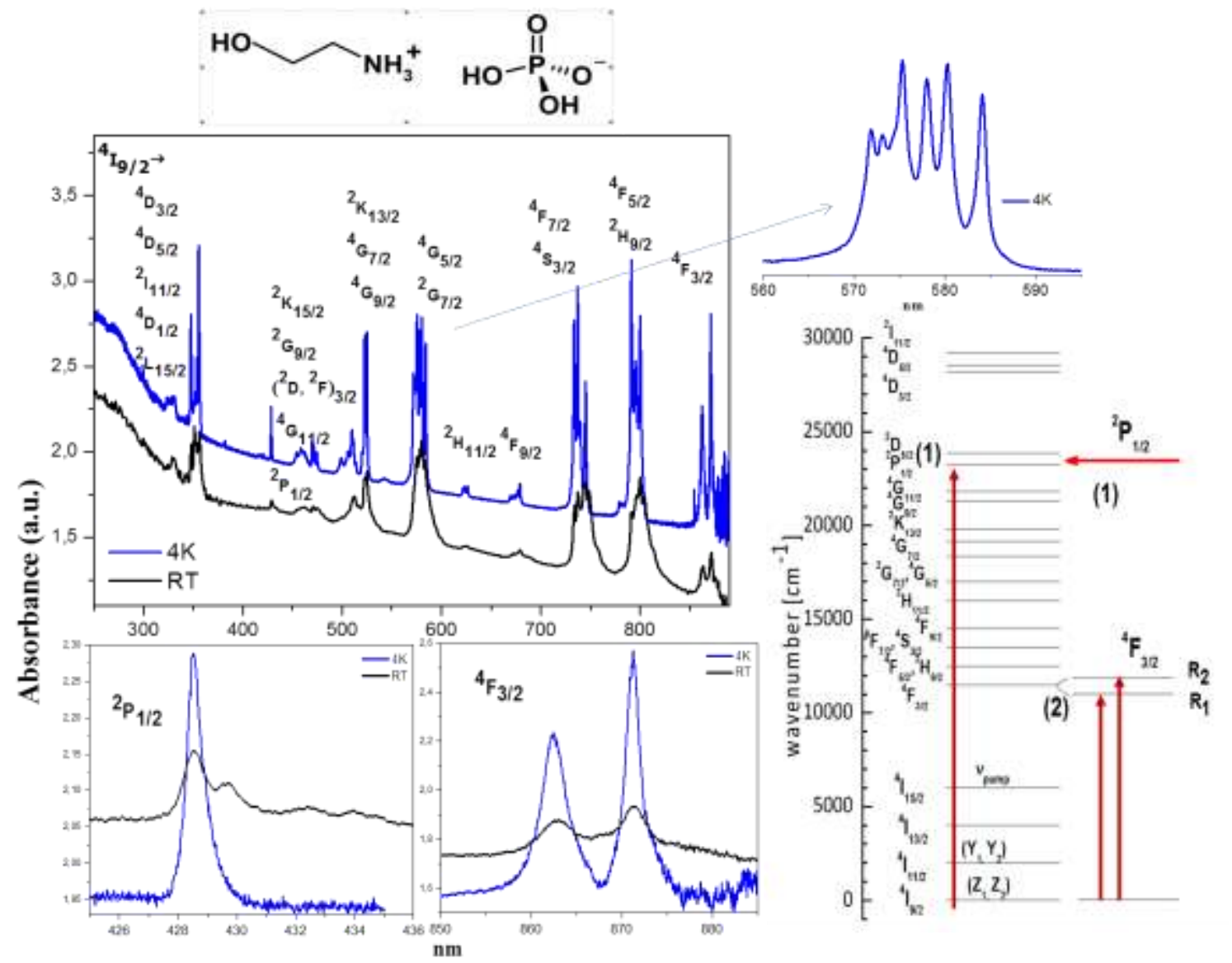

Fig. 8 Absorption spectra of $\mathrm{LaPO}_{4}: \mathrm{Nd}^{3+}($ choline $\left.] \mathrm{H}_{2} \mathrm{PO}_{4}\right)$ recorded at room and liquid helium temperature. 


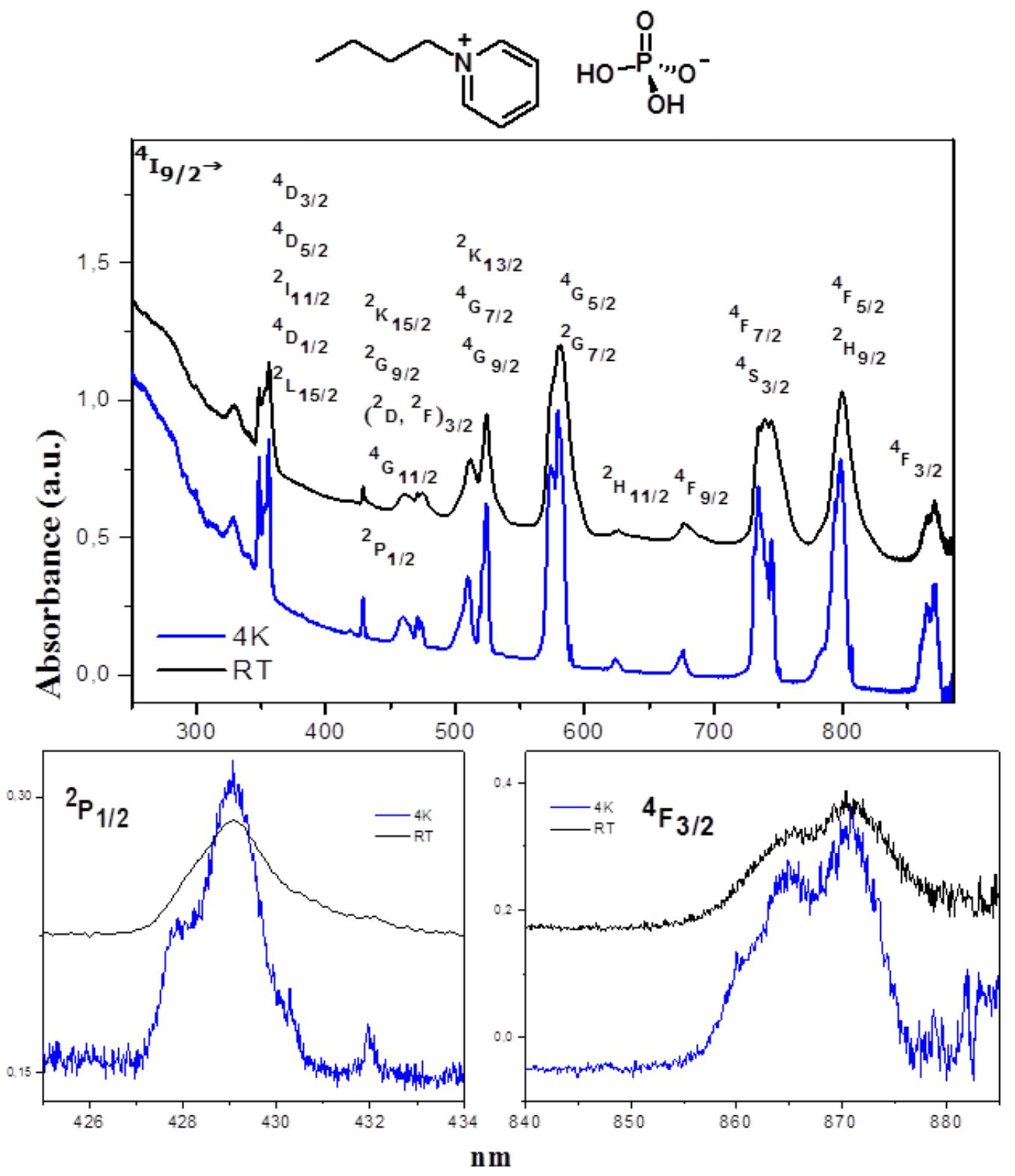

Fig. 9 Absorption spectra of $\mathrm{LaPO}_{4}: \mathrm{Nd}^{3+}\left(\mathrm{BmPyrH}_{2} \mathrm{PO}_{4}\right)$ recorded at room and liquid helium temperature 


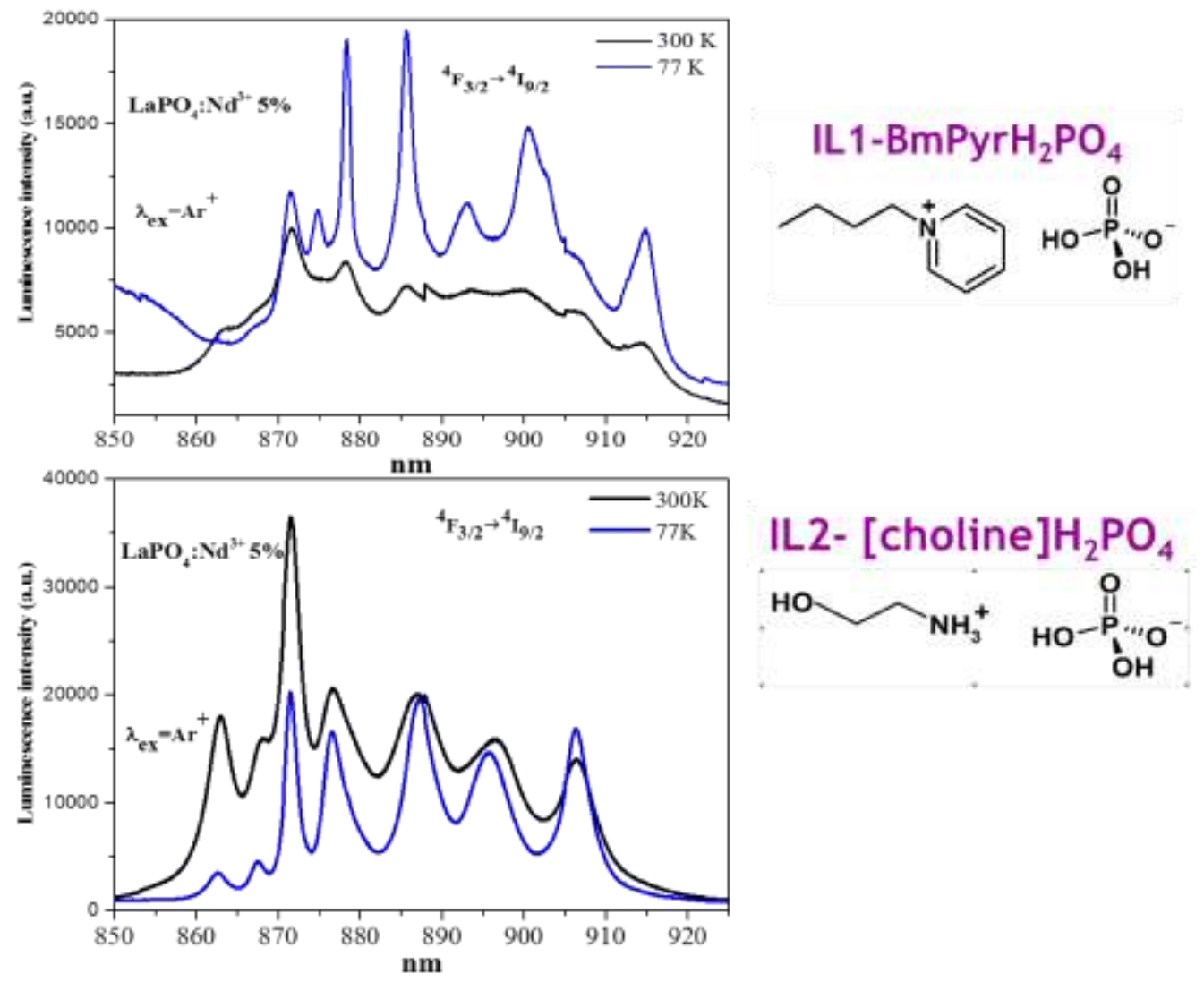

Fig. 10 Emission spectra of $\mathrm{LaPO}_{4}: \mathrm{Nd}^{3+} 5 \%$ recorded at room and $77 \mathrm{~K}$ under $\mathrm{Ar}^{+}$laser excitation, $\lambda_{\mathrm{ex}}=514 \mathrm{~nm}$. 


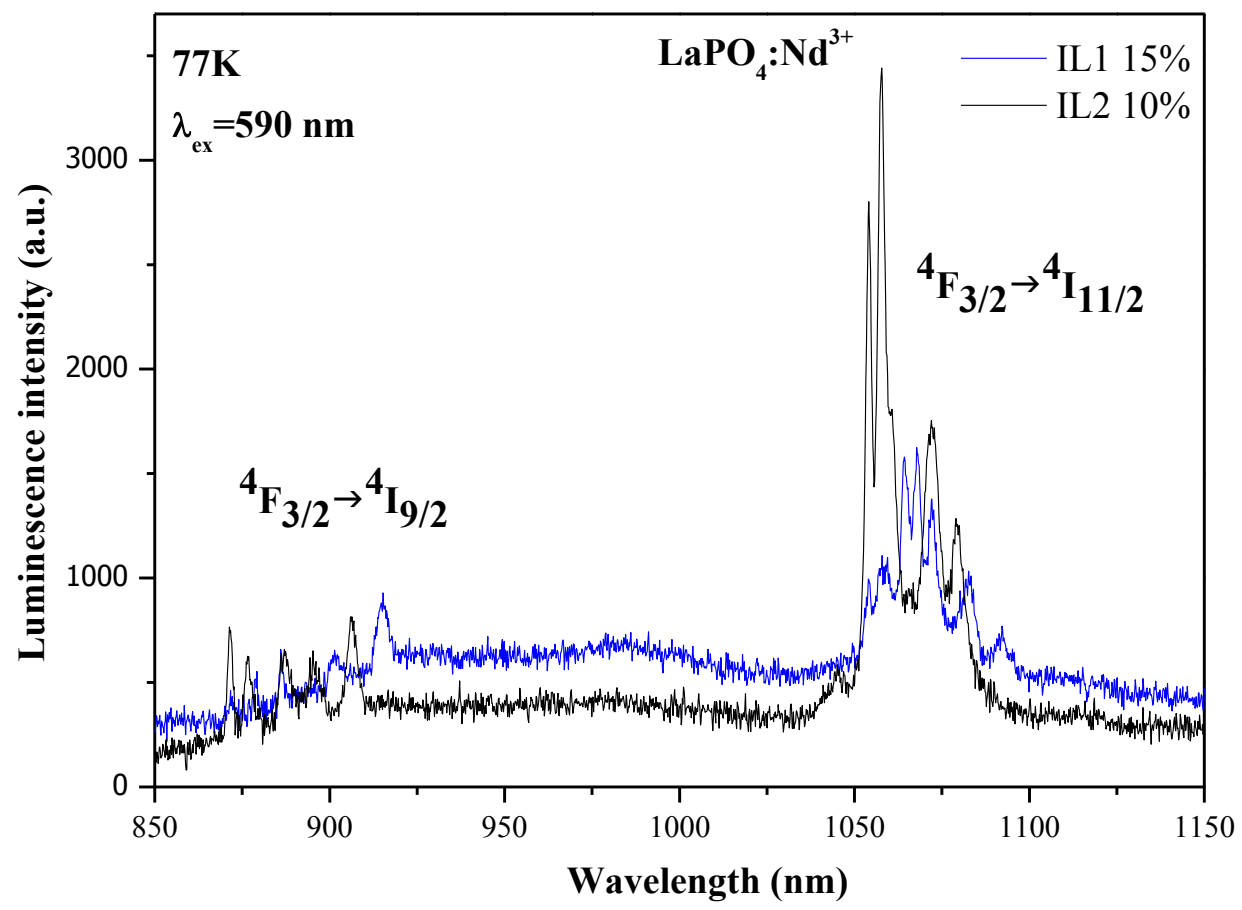

Fig. 11 Emission spectra of $\mathrm{Nd}^{3+}$ - doped $\mathrm{LaPO}_{4}$ containing 10 and $15 \mathrm{~mol} \%$ of activator recorded at $77 \mathrm{~K}, \lambda_{\mathrm{ex}}=590 \mathrm{~nm}$ of LED.

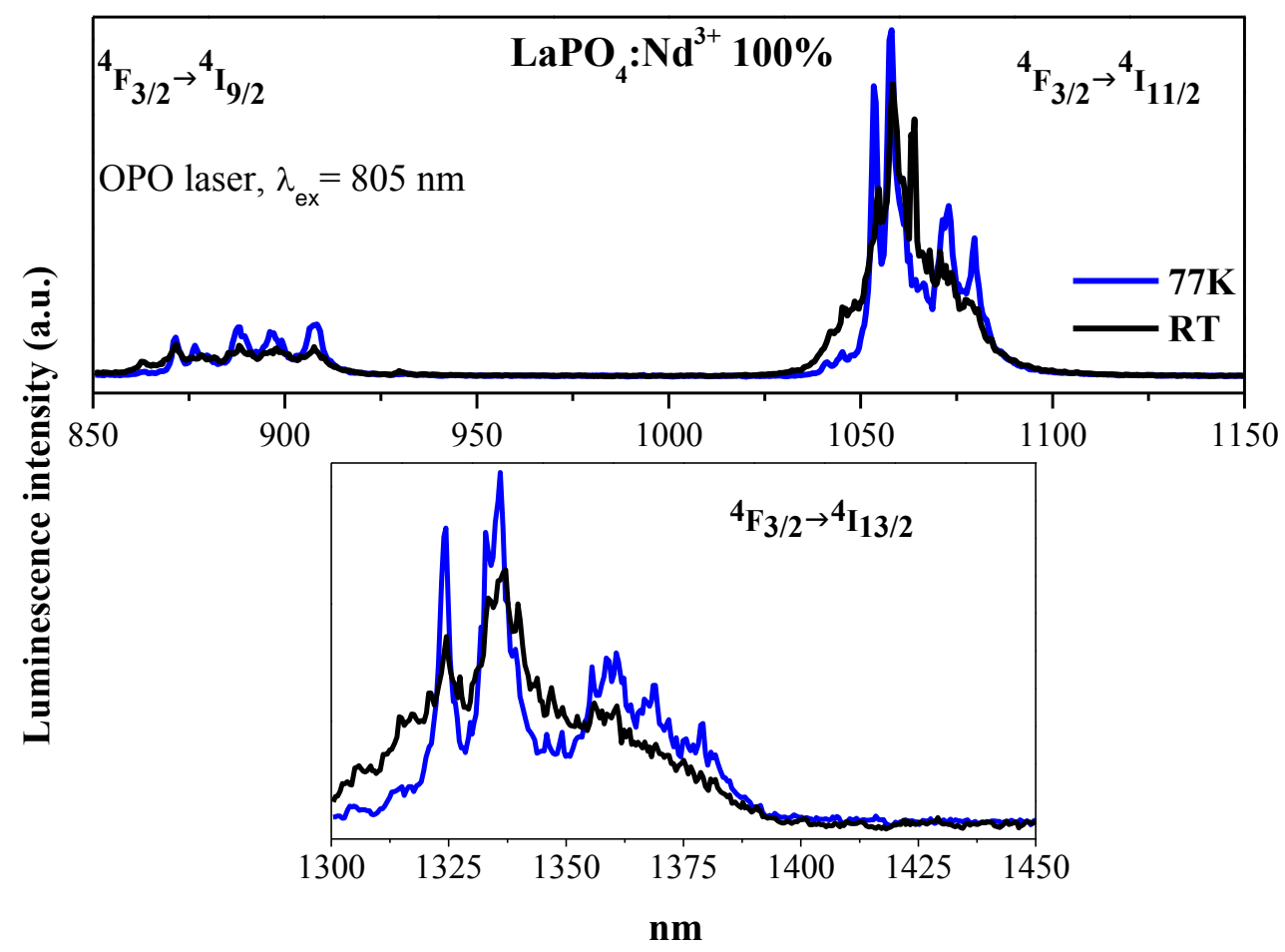

Fig. 12 Room and low temperature emission spectra of $\mathrm{NdPO}_{4}($ choline $\left.] \mathrm{H}_{2} \mathrm{PO}_{4}\right)$ under excitation with OPO laser, $\lambda_{\mathrm{ex}}=805 \mathrm{~nm}$ of LED. 

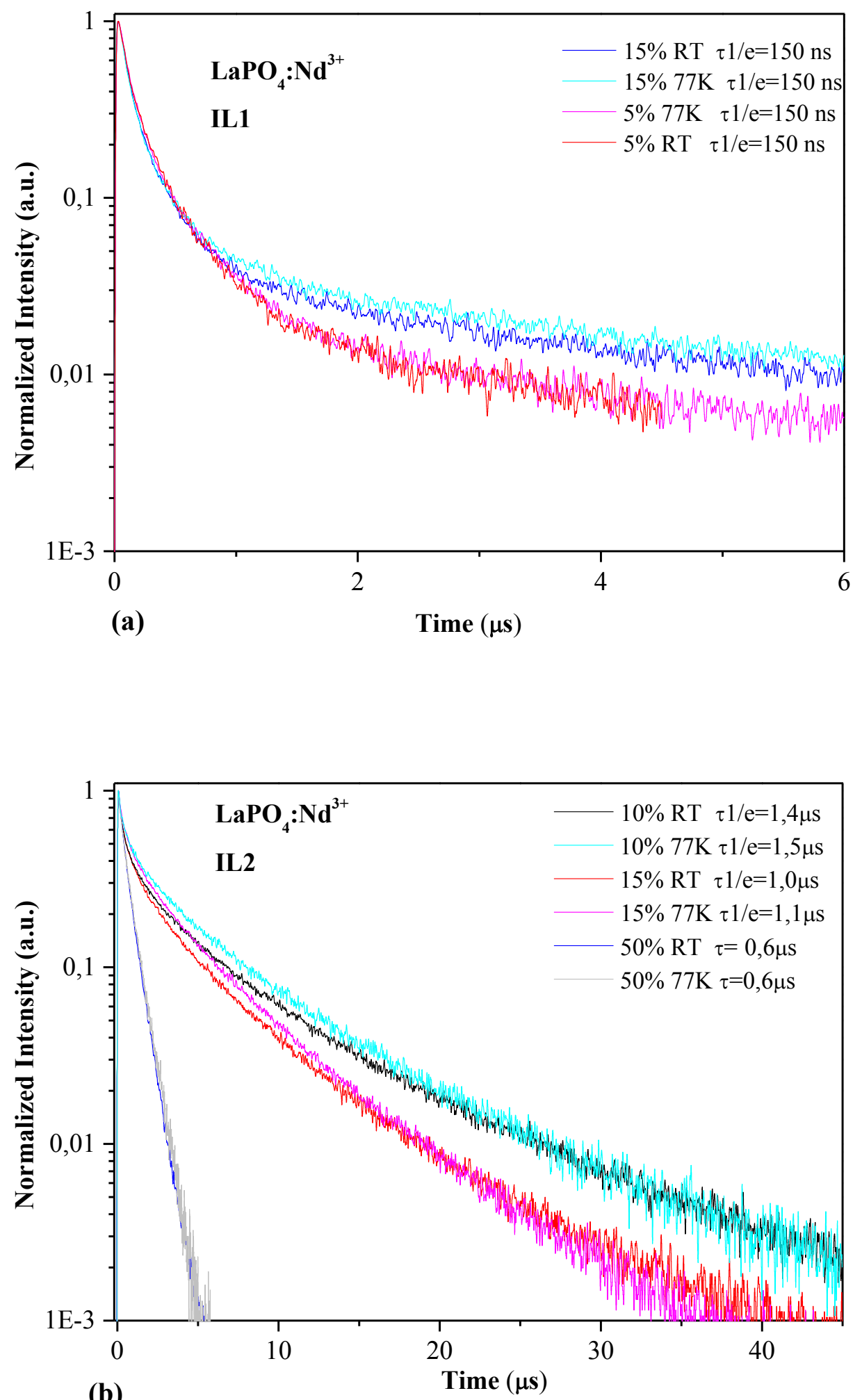

Fig. 13 Luminescence decays at room temperature and at $77 \mathrm{~K}$ of $\mathrm{Nd}^{3+4} \mathrm{~F}_{3 / 2}$ meta-stable level (at $\lambda_{\mathrm{em}}=1060 \mathrm{~nm}$ ) for $\mathrm{LaPO}_{4}$ (IL1-Fig. a) and (IL2-Fig.b) doped with different concentration of $\mathrm{Nd}^{3+}$ ions, $\lambda_{\mathrm{ex}}=581 \mathrm{~nm}$ of OPO laser. 


\section{Graphical abstract}
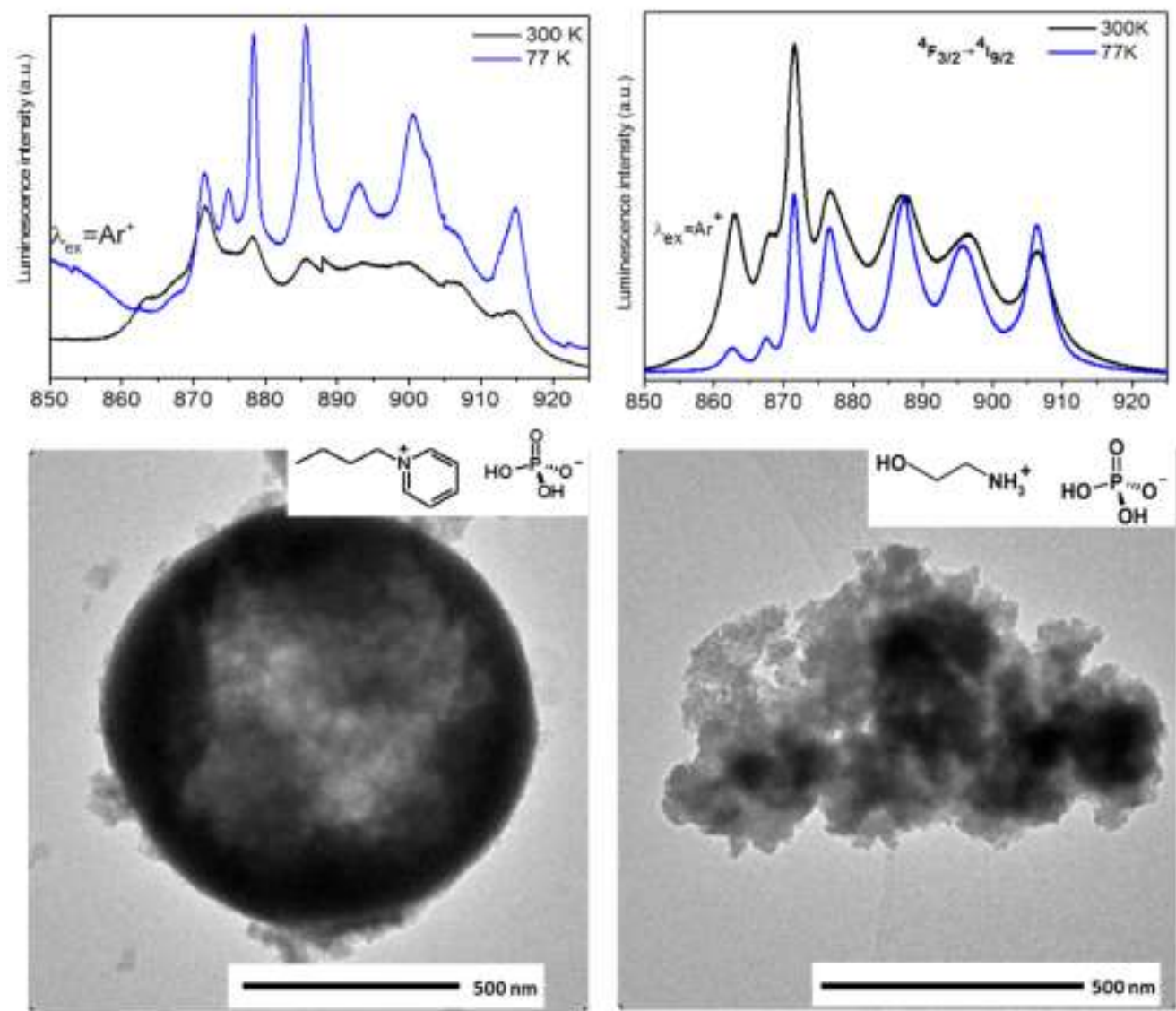